University of Nebraska - Lincoln

DigitalCommons@University of Nebraska - Lincoln

US Department of Energy Publications

U.S. Department of Energy

2012

\title{
The fundamental equation of eddy covariance and its application in flux measurements
}

Lianhong $\mathrm{Gu}$

Oak Ridge National Laboratory, Oak Ridge, TN

William J. Massman

Rocky Mountain Research Station, Fort Collins, CO

Ray Leuning

CSIRO Marine and Atmospheric Research, Canberra, ACT 2601, Australia

Stephen Pallardy

University of Missouri, Columbia, MO

Tilden Meyers

Atmospheric Turbulence and Diffusion Division, Air Resources Laboratory, NOAA, Oak Ridge, TN

See next page for additional authors

Follow this and additional works at: https://digitalcommons.unl.edu/usdoepub

Part of the Bioresource and Agricultural Engineering Commons

Gu, Lianhong; Massman, William J.; Leuning, Ray; Pallardy, Stephen; Meyers, Tilden; Hanson, Paul; Riggs, Jeffery; Hosman, Kevin; and Yang, Bai, "The fundamental equation of eddy covariance and its application in flux measurements" (2012). US Department of Energy Publications. 113.

https://digitalcommons.unl.edu/usdoepub/113

This Article is brought to you for free and open access by the U.S. Department of Energy at DigitalCommons@University of Nebraska - Lincoln. It has been accepted for inclusion in US Department of Energy Publications by an authorized administrator of DigitalCommons@University of Nebraska - Lincoln. 


\section{Authors}

Lianhong Gu, William J. Massman, Ray Leuning, Stephen Pallardy, Tilden Meyers, Paul Hanson, Jeffery Riggs, Kevin Hosman, and Bai Yang 


\title{
The fundamental equation of eddy covariance and its application in flux measurements
}

\author{
Lianhong $\mathrm{Gu}^{\mathrm{a}, *}$, William J. Massman ${ }^{\mathrm{b}}$, Ray Leuning ${ }^{\mathrm{c}}$, Stephen G. Pallardy ${ }^{\mathrm{d}}$, Tilden Meyers ${ }^{\mathrm{e}}$, \\ Paul J. Hanson ${ }^{\text {, }}$, Jeffery S. Riggs ${ }^{\text {a }}$, Kevin P. Hosman ${ }^{\text {d }}$, Bai Yang ${ }^{\text {a }}$ \\ a Environmental Sciences Division, Oak Ridge National Laboratory, Oak Ridge, TN 37831, USA \\ b USDA Forest Service, Rocky Mountain Research Station, 240 West Prospect, Fort Collins, CO 80526, USA \\ ' CSIRO Marine and Atmospheric Research, PO Box 3023, Canberra, ACT 2601, Australia \\ d Department of Forestry, University of Missouri, Columbia, MO 65211, USA \\ e Atmospheric Turbulence and Diffusion Division, Air Resources Laboratory, NOAA, Oak Ridge, TN 37830, USA
}

\section{A R T I C L E I N F O}

\section{Article history:}

Received 18 May 2011

Received in revised form

14 September 2011

Accepted 15 September 2011

\section{Keywords:}

Fundamental equation of eddy covariance WPL corrections

No net ecosystem source or sink of dry air Effective change in storage

\section{A B S T R A C T}

A fundamental equation of eddy covariance (FQEC) is derived that allows the net ecosystem exchange (NEE) $\overline{N_{s}}$ of a specified atmospheric constituent $s$ to be measured with the constraint of conservation of any other atmospheric constituent (e.g. $\mathrm{N}_{2}$, argon, or dry air). It is shown that if the condition $\left|\overline{N_{s}}\right| \gg$ $\left|\overline{\chi_{s}}\right|\left|\overline{N_{\mathrm{CO}_{2}}}\right|$ is true, the conservation of mass can be applied with the assumption of no net ecosystem source or sink of dry air and the FQEC is reduced to the following equation and its approximation for horizontally homogeneous mass fluxes:

$\overline{N_{s}}=\left.\overline{c_{d}} \overline{w^{\prime} \chi_{s}^{\prime}}\right|_{h}+\int_{0}^{h} \overline{c_{d}}(z) \overline{\frac{\partial \chi_{s}}{\partial t}} d z+\int_{0}^{h}\left[\overline{\chi_{s}}(z)-\overline{\chi_{s}}(h)\right] \overline{\frac{\partial c_{d}}{\partial t}} d z \approx \overline{c_{d}}(h)\left\{\left.\overline{w^{\prime} \chi_{s}^{\prime}}\right|_{h}+\int_{0}^{h} \overline{\frac{\partial \chi_{s}}{\partial t}} d z\right\}$.

Here $w$ is vertical velocity, $c$ molar density, $t$ time, $h$ eddy flux measurement height, $z$ vertical distance and $\chi_{s}=c_{s} / c_{d}$ molar mixing ratio relative to dry air. Subscripts $s, d$ and $\mathrm{CO}_{2}$ are for the specified constituent, dry air and carbon dioxide, respectively. Primes and overbars refer to turbulent fluctuations and time averages, respectively. This equation and its approximation are derived for non-steady state conditions that build on the steady-state theory of Webb, Pearman and Leuning (WPL; Webb et al., 1980. Quart. J. R. Meteorol. Soc. 106, 85-100), theory that is widely used to calculate the eddy fluxes of $\mathrm{CO}_{2}$ and other trace gases. The original WPL constraint of no vertical flux of dry air across the EC measurement plane, which is valid only for steady-state conditions, is replaced with the requirement of no net ecosystem source or sink of dry air for non-steady state conditions. This replacement does not affect the 'eddy flux' term $\overline{c_{d}} \overline{W^{\prime} \chi_{s}^{\prime}}$ but requires the change in storage to be calculated as the 'effective change in storage' as follows:

$\int_{0}^{h} \overline{\frac{\partial c_{s}}{\partial t}} d z-\overline{\chi_{s}}(h) \int_{0}^{h} \overline{\frac{\partial c_{d}}{\partial t}} d z=\int_{0}^{h} \overline{c_{d}}(z) \overline{\frac{\partial \chi_{s}}{\partial t}} d z+\int_{0}^{h}\left[\overline{\chi_{s}}(z)-\overline{\chi_{s}}(h)\right] \overline{\frac{\partial c_{d}}{\partial t}} d z \approx \overline{c_{d}}(h) \int_{0}^{h} \overline{\frac{\partial \chi_{s}}{\partial t}} d z$.

Without doing so, significant diurnal and seasonal biases may occur. We demonstrate that the effective change in storage can be estimated accurately with a properly designed profile of mixing ratio measurements made at multiple heights. However further simplification by using a single measurement at the EC instrumentation height is shown to produce substantial biases. It is emphasized that an adequately designed profile system for measuring the effective change in storage in proper units is as important as the eddy flux term for determining NEE.

(C) 2011 Elsevier B.V. All rights reserved.

\footnotetext{
is This manuscript has been co-authored by CSIRO, Australia, USDA Forest Service, NOAA ATDD, and UT-Battelle, LLC, under Contract No. DE-AC05-00OR22725 with the U.S. Department of Energy. The United States Government retains and the publisher, by accepting the article for publication, acknowledges that the United States Government retains a non-exclusive, paid-up, irrevocable, world-wide license to publish or reproduce the published form of this manuscript, or allow others to do so, for United States Government purposes.

* Corresponding author at: Environmental Sciences Division, Building 2040, Oak Ridge National Laboratory, Oak Ridge, TN 37831-6301, USA. Tel.: +1 865 241 5925.

E-mail address: lianhong-gu@ornl.gov (L. Gu).
} 
When the EC instrumentation measures densities rather than mixing ratios, it is necessary to use:

$\left.\overline{N_{s}} \approx \overline{w^{\prime} c_{s}^{\prime}}\right|_{h}+\overline{\chi_{s}}\left[\overline{w^{\prime} c_{v}^{\prime}}+\bar{c} \frac{\overline{w^{\prime} T^{\prime}}}{\bar{T}}\right]_{h}+\overline{c_{d}}(h) \int_{0}^{h} \frac{\overline{\partial \chi_{s}}}{\partial t} d z$.

Here $T$ is temperature and $c_{v}$ and $c$ are the molar densities of water vapor and moist air, respectively. For some atmospheric gas species such as $\mathrm{N}_{2}$ and $\mathrm{O}_{2}$, the condition $\left|\overline{N_{s}}\right| \gg\left|\overline{\chi_{s}}\right|\left|\overline{N_{\mathrm{CO}_{2}}}\right|$ is not satisfied and additional information is needed in order to apply the EC technique with the constraint of conservation of dry air.

(C) 2011 Elsevier B.V. All rights reserved.

\section{Introduction}

Flux measurements of trace gases, water vapor, and sensible heat with the eddy covariance (EC) technique play an important role in the fields of climate change, global change biology and ecology. Such measurements are routinely used for understanding ecosystem function, estimating terrestrial carbon budgets, testing ecosystem and land surface models, and predicting ecosystem responses to changes in mean and extreme climate conditions. However, the EC technique in its present state has several recognized problems. For example, it is unable to close the energy budget (e.g. Wilson et al., 2002) and apparently underestimates nighttime ecosystem respiration (e.g. Goulden et al., 1996; Gu et al., 2005). The nearly universal occurrence of these problems across flux sites with diverse vegetation and topographical characteristics requires periodic reexamination of the fundamental assumptions applied in the EC technique.

EC flux measurements of atmospheric constituents require constraints to compensate for inadequate accuracy in measured variables as well as for other issues. The principle guiding the current practice of EC measurements was laid out by Webb, Pearman and Leuning (WPL) in 1980 (Webb et al., 1980; Lee and Massman, 2011). The WPL's seminal theory assumed 'no source or sink of (dry) air at the ground' and as a result implemented a constraint of no vertical flux of dry air (defined as the mixture of all atmospheric constituents other than water vapor) across the EC measurement plane. Consequently, WPL 1980 was limited to the case of horizontally homogeneous mass fluxes under steady-state conditions (no temperature/pressure changes). Nevertheless, the theory has been applied widely even though the constraint of no vertical flux of dry air is invalid for non-steady state conditions, when changes in density associated with changes in temperature and pressure lead to a non-zero flux of dry air and other gases through the EC measurement plane. Fluxes of a specified atmospheric constituent thus consist of one component due to atmospheric dry air density changes that is not of particular interest, and another due to the net exchanges between the ecosystem and the atmosphere that we do wish to know. Flux measurements will be biased, diurnally and seasonally, if the non-zero vertical flux of dry air is not taken into consideration. These biases can be eliminated by careful examination of all terms in the mass conservation equation, which can be expressed in terms of mass densities, molar densities or mixing ratios. As shown below, the number of terms in the equation varies with the units chosen and this outcome affects how field measurements need to be analyzed to give the correct results.

Several authors have already realized the need to generalize the steady-state theory of WPL 1980 so that non-steady state conditions can be considered. Leuning (2004, 2007) developed mass balance equations for a trace quantity with the assumption of no net ecosystem source or sink of dry air. Kowalski and Serrano-Ortiz (2007) pointed out the assumption of zero dry air flux is invalid except right at the soil surface boundary. Lee and Massman (2011) applied the equation of continuity of dry air with zero source (Paw et al., 2000) and the assumption of no dry air flux at the soil surface to derive equations for flux measurements. Note that the treatment of Lee and Massman (2011) and the assumption of Leuning (2004, 2007) are equivalent.

In the present study, we build upon these contributions. We broaden the eddy covariance theory by deriving a fundamental equation of eddy covariance that allows the net ecosystem exchange of a specified atmospheric constituent such as $\mathrm{CO}_{2}$ and water vapor between the surface and atmosphere to be measured with the constraint of conservation of mass of any other atmospheric constituent. Candidate constituents that are suitable for use to constrain flux measurements are suggested. The application of the conservation of dry air for flux measurements is then seen as a special case of the fundamental equation of eddy covariance. We also establish the condition under which the assumption of no net ecosystem source or sink of dry air can be made without substantial errors in measured fluxes. It is shown that for some atmospheric gas species this assumption is not valid; for these species, we identify what additional information is needed in order to measure their fluxes with the EC technique. Biases caused by applying the steady-state theory for non-steady state conditions are assessed and certain unstated, simplifying assumptions in previous studies are clarified and investigated with observations from a flux site. Finally we show that measurements of change in storage through an adequately designed profile system and in proper units are as important as the eddy flux term for accurate determination of NEE.

\section{The fundamental equation of eddy covariance}

\subsection{The derivation of the equation}

Ever since WPL 1980, dry air has played a central role in eddy flux measurements of atmospheric constituents. On first thought, this sounds quite unusual: why should measuring the flux of one atmospheric constituent have anything to do with a constantly changing admixture of all non- $\mathrm{H}_{2} \mathrm{O}$ atmospheric constituents most of which are not even measured? The answer to this question may seem obvious but its illumination is helpful to understanding the eddy covariance theory. Here it is shown that dry air comes into play only as a matter of convenience and the fundamental equation of eddy covariance (FQEC) can be formulated without invoking dry air at all. The FQEC can be derived either through the holistic mass balance approach or through the equation of continuity of an atmospheric constituent. These two approaches are equivalent. Here the FQEC for horizontally homogeneous mass fluxes is derived with the holistic mass balance approach. In Appendix A, the general FQEC for non-homogeneous mass fluxes is derived from equation of continuity.

For a layer of horizontally homogeneous air flows above the soil surface in which horizontal advection can be ignored, the conservation of mass dictates that the net ecosystem exchange (NEE) $\overline{N_{S}}$ $\left(\mathrm{mol} \mathrm{m}^{-2} \mathrm{~s}^{-1}\right)$ of a specified atmospheric constituent $s$ is balanced 
by its total vertical flux $\overline{w c_{s}}$ across the EC measurement plane at height $h$ and total change in storage with time $t$ below that height:

$\overline{N_{s}}=\left.\overline{w c_{s}}\right|_{h}+\int_{0}^{h} \overline{\frac{\partial c_{s}}{\partial t}} d z$

Here $w$ refers to vertical wind velocity, $c_{s}$ to molar density $\left(\mathrm{mol} \mathrm{m}^{-3}\right)$ of the specified constituent, and $z$ to vertical distance from the soil surface. Overbars indicate time averages. Symbols and subscripts are listed in Appendix B. Note that $\overline{N_{s}}$ includes contributions from both plant canopy and soil (see Appendix A). Also Eq. (1) applies only to nonreactive gas species. For a reactive gas species, the right hand side of Eq. (1) is equal to the biochemically produced $\overline{N_{s}}$ plus any sink/source of the species of photo (and other)-chemical origins. Vilà-Guerau de Arellano et al. (1995) studied the flux-gradient relationships of chemically reactive species. The present study considers only nonreactive gas species. Later when the oxygen molecules $\left(\mathrm{O}_{2}\right)$ are discussed in the context of eddy covariance theory, their participation in photochemical reactions in the atmosphere will be ignored.

EC instrumentation measures both $w$ and $c_{s}$. A naïve thought might be to insert the directly measured $w$ and $c_{s}$ into Eq. (1) and calculate $\overline{N_{S}}$ in a straightforward way. One reason for not doing so as explained in WPL 1980 is still valid for today's EC instrumentation: $w$ cannot be measured with sufficient accuracy. Additional information is needed to constrain or condition Eq. (1). To see what additional information is needed, we apply the Reynolds decomposition rules to the total vertical flux:

$$
\left.\overline{w c_{s}}\right|_{h}=\left.\overline{w^{\prime} c_{s}^{\prime}}\right|_{h}+\left.\bar{w} \overline{c_{s}}\right|_{h} .
$$

Here the rapid turbulent fluctuations (primed variables) have been separated from their corresponding means (overbarred variables). The total vertical flux now consists of two terms: a covariance term and a mean vertical advective flux term. Any additive bias errors in the measured $w$ and $c_{s}$ will not affect the covariance term which can therefore be used directly as part of the total vertical flux. However such errors will affect the mean vertical advective flux term $\bar{w} \overline{c_{S}}$ and additional information is needed to constrain or replace it.

Now suppose the NEE $\overline{N_{d}}$ of another atmospheric constituent, $d$, called the constraining constituent, is known a priori. Thus, we can write:

$$
\begin{aligned}
\overline{N_{d}}= & \left.\overline{w c_{d}}\right|_{h}+\int_{0}^{h} \frac{\overline{\partial c_{d}}}{\partial t} d z=\left.\overline{w^{\prime} c_{d}^{\prime}}\right|_{h}+\left.\bar{w} \overline{c_{d}}\right|_{h}+\int_{0}^{h} \overline{\frac{\partial c_{d}}{\partial t}} d z=\left.\overline{w^{\prime} c_{d}^{\prime}}\right|_{h} \\
& +\left.\bar{w} \overline{c_{s}} \overline{\overline{c_{d}}}\right|_{h}+\int_{0}^{h} \frac{\overline{\partial c_{d}}}{\partial t} d z .
\end{aligned}
$$

Solving for the mean vertical advective flux $\bar{w} \overline{c_{s}}$ results in

$\left.\bar{w} \overline{c_{s}}\right|_{h}=\overline{\chi_{s}}(h)\left(-\left.\overline{w^{\prime} c_{d}^{\prime}}\right|_{h}+\overline{N_{d}}-\int_{0}^{h} \overline{\frac{\partial c_{d}}{\partial t}} d z\right)$.

Here $\chi_{s}$ is the molar density ratio of $s$ relative to the constraining constituent $\left(\chi_{s}=c_{s} / c_{d}\right)$. The mean vertical advective flux of $s$ is now expressed as the product of the molar density ratio and a term that is entirely defined by the constraining constituent. Substituting (4) into (2) yields the total vertical flux of $s$ :

$$
\left.\overline{w c_{s}}\right|_{h}=\left.\overline{w^{\prime} c_{s}^{\prime}}\right|_{h}+\overline{\chi_{s}}(h)\left(-\left.\overline{w^{\prime} c_{d}^{\prime}}\right|_{h}+\overline{N_{d}}-\int_{0}^{h} \overline{\frac{\partial c_{d}}{\partial t}} d z\right)
$$

Noting $c_{s}^{\prime}=\overline{\chi_{s}} c_{d}^{\prime}+\overline{c_{d}} \chi_{s}^{\prime}$ as a result of linearization, we can rewrite (5) in the form of molar density ratio of $s$ relative to the constraining constituent:

$\left.\overline{w c_{s}}\right|_{h}=\underbrace{\left.\overline{c_{d}} \overline{w^{\prime} \chi_{s}^{\prime}}\right|_{h}}_{\mathrm{I}}+\underbrace{\overline{\chi_{s}}(h) \overline{N_{d}}}_{\mathrm{II}} \underbrace{\overline{\chi_{s}}(h) \int_{0}^{h} \overline{\frac{\partial c_{d}}{\partial t}} d z}_{\text {III }}$.

Eq. (6) shows that the total vertical flux of $s$ across the EC measurement plane at $h$ contains three parts: (I) the eddy flux - the covariance between vertical wind velocity and molar density ratio, multiplied by the molar density of the constraining constituent; (II) a correction due to the net ecosystem source/sink of the constraining constituent, which is termed 'constraining constituent source/sink correction'; and (III) a component due to the time change in storage of the constraining constituent below $h$, which is termed 'constraining constituent storage adjustment'. A key insight from Eq. (6) is that the eddy flux is only part of the total vertical flux across the EC measurement plane.

The NEE of $s$ can now be expressed either as

$\overline{N_{s}}=\left.\overline{w^{\prime} c_{s}^{\prime}}\right|_{h}+\int_{0}^{h} \overline{\frac{\partial c_{s}}{\partial t}} d z+\overline{\chi_{s}}(h)\left(-\left.\overline{w^{\prime} c_{d}^{\prime}}\right|_{h}+\overline{N_{d}}-\int_{0}^{h} \overline{\frac{\partial c_{d}}{\partial t}} d z\right)$,

or as

$\overline{N_{s}}=\underbrace{\left.\overline{c_{d}} \overline{w^{\prime} \chi_{s}^{\prime}}\right|_{h}}_{\mathrm{I}}+\underbrace{\overline{\chi_{s}}(h) \overline{N_{d}}}_{\text {II }}+\underbrace{\int_{0}^{h} \overline{\frac{\partial c_{s}}{\partial t}} d z-\overline{\chi_{s}}(h) \int_{0}^{h} \overline{\frac{\partial c_{d}}{\partial t}} d z}_{\text {III }}$.

The net exchange of $s$ with the atmosphere is the sum of: (I) the eddy flux, (II) the flux of $s$ associated with $\overline{N_{d}}$, and (III) the total change in mass of $s$ stored in the air column below $h$ minus the change in mass of $s$ arising from heating, cooling or change in atmospheric pressure within the air column. From now on, we will call term III the 'effective change in storage' of $s$. The concept of effective change in storage acknowledges that part of the total change in storage of $s$ below $h$ and therefore part of the total vertical flux of $s$ at $h$ are not caused by the biological processes of the ecosystem and are not part of the NEE of $s$. As shown later, the physical meaning of term III will become clearer when changes in storage are expressed in terms of molar density ratios.

In the derivation above, the WPL 1980 concept of mean vertical velocity is not invoked. The use of the concept of thermal expansion velocity of Lee and Massman (2011) is also avoided. For the purpose of comparison with these previous studies, we note that both the WPL velocity and the thermal expansion velocity are inseparable part of the diagnostic mean vertical bulk velocity $(\bar{w})$. This diagnostic velocity is responsible for the mean vertical advective flux in the total vertical flux (see Eq. (2)) and given by

$$
\frac{1}{\overline{c_{s}(h)}}\left(-\left.\overline{w^{\prime} c_{s}^{\prime}}\right|_{h}+\overline{N_{s}}-\int_{0}^{h} \overline{\frac{\partial c_{s}}{\partial t}} d z\right)=\frac{1}{\overline{{c_{d}}(h)}}\left(-\left.\overline{w^{\prime} c_{d}^{\prime}}\right|_{h}+\overline{N_{d}}-\int_{0}^{h} \overline{\frac{\partial c_{d}}{\partial t}} d z\right) .
$$

This identity is obtained by manipulating Eq. (7). Note that the subscripts $s$ and $d$ can refer to any atmospheric constituent and the two sides of the identity are symmetrical in form. Eq. (9) expresses the coupling in atmospheric transport of different atmospheric constituents. It indicates the basis upon which the flux measurements of a specified atmospheric constituent are ultimately constrained: no matter what processes are responsible for the presence of a nonzero mean vertical bulk velocity, this velocity must be identical for each and every atmospheric constituent.

Eqs. (7) and (8) are derived with a minimum number of assumptions. Either equation can be termed the fundamental equation of eddy covariance for horizontally homogeneous mass fluxes. In 
Appendix A, the general FQEC for non-homogeneous mass fluxes is derived and is reproduced here:

$$
\begin{aligned}
\overline{N_{s}} & =\left.\overline{c_{d}} \overline{w^{\prime} \chi_{s}^{\prime}}\right|_{h}+\overline{\chi_{s}}(h) \overline{N_{d}}+\left\{\int_{0}^{h} \overline{\frac{\partial c_{s}}{\partial t}} d z-\overline{\chi_{s}}(h) \int_{0}^{h} \overline{\frac{\partial c_{d}}{\partial t}} d z\right\} \\
+ & \underbrace{\left\{\int_{0}^{h} \nabla_{H} \cdot\left(\overline{\mathbf{u} c_{d}} \overline{\chi_{s}}+\overline{c_{d}} \overline{\mathbf{u}^{\prime} \chi_{s}^{\prime}}\right) d z-\overline{\chi_{s}}(h) \int_{0}^{h} \nabla_{H} \cdot\left(\overline{\mathbf{u} c_{d}}\right) d z\right\}}_{\text {horizontal advection }}
\end{aligned}
$$

Here $\mathbf{u}$ is the $2 \mathrm{D}$ horizontal velocity field and $\nabla_{H}$ is the 2D horizontal gradient operator. Compared with the FQEC for horizontally homogeneous mass fluxes, the general FQEC contains a term for horizontal advection.

\subsection{Choices of the constraining constituent}

The derivation of the FQEC in Section 2.1 and in Appendix A shows that in theory it is unnecessary to restrict the selection of the constraining constituent to dry air. The conservation of mass of any atmospheric constituent can be used to constrain flux measurements with the eddy covariance technique as long as its net ecosystem exchange with the atmosphere is known a priori. However, there is a practical advantage in using dry air: one does not need an extra gas analysis system besides those that measure the constituent $s$ and water vapor whose net ecosystem exchanges are our interest. With an open gas analysis system for $s$ and water vapor, $\overline{w^{\prime} c_{d}^{\prime}}$ in Eq. (7) is replaced with the measurable moisture covariance $\overline{w^{\prime} c_{v}^{\prime}}$ and temperature covariance $\overline{w^{\prime} T^{\prime}}$. This is done by using $c_{d}=c-c_{v}$ and the equation of state for moist air $c=P / R T$ ( $c$ is moist air molar density, $P$ total atmospheric pressure, and $R$ universal gas constant) as in WPL 1980. After some manipulation, Eq. (7) changes to

$$
\begin{aligned}
\overline{N_{s}}= & \left.\overline{w^{\prime} c_{s}^{\prime}}\right|_{h}+\overline{\chi_{s}}\left[\overline{w^{\prime} c_{v}^{\prime}}+\bar{c} \frac{\overline{w^{\prime} T^{\prime}}}{\bar{T}}\right]_{h}+\overline{\chi_{s}}(h) \overline{N_{d}} \\
& +\int_{0}^{h} \overline{\frac{\partial c_{s}}{\partial t}} d z-\overline{\chi_{s}}(h) \int_{0}^{h} \overline{\frac{\partial c_{d}}{\partial t}} d z .
\end{aligned}
$$

Here $\chi_{s}$ becomes the molar mixing ratio of $s$ relative to dry air. To derive Eq. (11), the covariance between the vertical velocity and pressure $P$ is neglected. Also linearization is applied to avoid additional terms related to higher order fluctuations (beyond variances and covariances) in measured quantities (Fuehrer and Friehe, 2002). Unlike Eqs. (7) and (8), Eq. (11) is valid only when the conservation of dry air is used to constrain flux measurements.

The advantage of using dry air as the constraining constituent can also be its potential weakness. Dry air contains numerous gases and its composition varies with time. There are no fast response technologies to measure its density directly. When the ideal gas law is used to compute dry air density, additional measurements in atmospheric pressure, temperature and water vapor density are needed (see Eq. (11)). Errors in these measurements propagate into the calculated dry air density and covariances and thus fluxes of the specified atmospheric constituent. Furthermore, the use of dry air necessitates repeated application of linearization, a process that neglects contribution to calculated fluxes of higher order fluctuations in measured quantities (Fuehrer and Friehe, 2002). If a single atmospheric gas is used as the constraining constituent and its density is measured directly, the FQEC Eq. (7) is applied without the need of any indirect calculation or linearization. The elimination of uncertainties associated with indirect calculation and linearization will result in more accurate flux measurements.
$\mathrm{N}_{2}$ and argon are potentially good choices as the constraining constituent. $\mathrm{N}_{2}$ is the most abundant constituent in the atmosphere and argon is the third. Except for $\mathrm{O}_{2}$, the molar density ratio of any atmospheric gas species to that of $\mathrm{N}_{2}$ or argon is far less than 1. Ecosystems exchange $\mathrm{N}_{2}$ with the atmosphere as a result of nitrogen fixation, nitrification and denitrification. But typical net exchange rates of $\mathrm{N}_{2}$ from all processes are only in the range of tens of nanomoles per meter square per second (Meijide et al., 2010; Welsh et al., 2000). Argon is an inert gas and no known ecosystem processes are involved in its absorption or production. Therefore when $\mathrm{N}_{2}$ or argon is used as the constraining constituent, the constraining constituent source/sink correction term $\overline{\chi_{s}} \overline{N_{d}}$ is likely very small in comparison with the flux of any specified atmospheric constituent, and thus can be ignored. This is a benefit in addition to that no indirect calculation or linearization is necessary. Research in this direction may advance the eddy covariance technique. For the present study, however, we focus on the use of dry air as the constraining constituent.

\section{Approximations to the fundamental equation of eddy covariance}

\subsection{The constraint of no net ecosystem source/sink of dry air}

No matter whether the constraint of no vertical flux of dry air or that of no net ecosystem source/sink of dry air is applied, an apparent contradiction exists. If one wants to measure the flux of a non-water vapor atmospheric constituent, which is always part of dry air, is it not already implied that the vertical flux of dry air or the net ecosystem exchange of dry air is not zero? This contradiction is resolved with an analysis of the complete ecosystem budget of dry air and its effect on flux measurements. The analysis also leads to some new insights about the eddy covariance technique when dry air is used as the constraining constituent.

Terrestrial ecosystems affect the boundary-layer budget of dry air mainly through the exchanges of $\mathrm{CO}_{2}$ and $\mathrm{O}_{2}$. On time scales relevant for flux measurements (minutes to hours), the exchanges of these two gases are not balanced and do not cancel their contributions to the budget of dry air. This is because several biological processes, in addition to photosynthetic assimilation, are involved in the determination of the ecosystem $\mathrm{O}_{2}: \mathrm{CO}_{2}$ molar exchange ratio $k$ which can vary from 0.7 to 1.6 (Seibt et al., 2004). Besides $\mathrm{CO}_{2}$ and $\mathrm{O}_{2}$, ecosystems may absorb or emit trace gases such as $\mathrm{N}_{2}$, $\mathrm{N}_{2} \mathrm{O}, \mathrm{NO}_{x}$ (Galbally et al., 2010; Meijide et al., 2010), $\mathrm{CH}_{4}$ in wetlands (McDermitt et al., 2011; Tuzson et al., 2010), carbonyl sulfide (Campbell et al., 2008), CO (Galbally et al., 2010; King and Crosby, 2002) and isoprene $\left(\mathrm{C}_{5} \mathrm{H}_{8}\right.$, Fuentes et al., 1999). $\overline{\mathrm{N}_{\mathrm{CO}_{2}}}$ and $\overline{\mathrm{N}_{\mathrm{O}_{2}}}$ are in the order of $10 \mu \mathrm{mol} \mathrm{m}^{-2} \mathrm{~s}^{-1}$ whereas measured fluxes of other trace gases produced by ecosystems generally are in the order of $10 \mathrm{pmol} \mathrm{m}^{-2} \mathrm{~s}^{-1}$ to $10 \mathrm{nmol} \mathrm{m}^{-2} \mathrm{~s}^{-1}$. Therefore the net ecosystem exchange of dry air is likely dominated by the stoichiometric imbalance between $\mathrm{O}_{2}$ and $\mathrm{CO}_{2}$ exchanges with minor contributions from other trace gases. Its typical value is likely in the range of tens of micromoles per meter square per second. Therefore some error will be introduced if the conservation of mass of dry air is used as a constraint in measuring fluxes of atmospheric constituents with the assumption of no net ecosystem source/sink of dry air $\left(\overline{N_{d}}=0\right)$.

To assess the magnitude of error introduced by assuming $\overline{N_{d}}=0$, suppose dry air consists of $n$ individual gases each of which has a net exchange between the ecosystem and atmosphere.

$\overline{N_{d}}=\sum_{i=1}^{n} \overline{N_{i}}=\overline{N_{\mathrm{CO}_{2}}}+\overline{N_{\mathrm{O}_{2}}}+\sum_{i=3}^{n} \overline{N_{i}}=(1-k) \overline{N_{\mathrm{CO}_{2}}}+\sum_{i=3}^{n} \overline{N_{i}}$.

Here $\mathrm{CO}_{2}$ and $\mathrm{O}_{2}$ are separated from other dry air components because their net exchanges are much larger than those of others 
and are stoichiometrically coupled. The negative sign preceding $k$ indicates $\mathrm{O}_{2}$ and $\mathrm{CO}_{2}$ exchanges are in opposing directions. Substituting $\overline{N_{d}}$ in Eq. (8) and collecting terms yields:

$$
\begin{aligned}
\overline{N_{s}}\left[1-\overline{\chi_{s}}(h)\right]= & \left.\overline{c_{d}} \overline{w^{\prime} \chi_{s}^{\prime}}\right|_{h}+\overline{\chi_{s}}(h) \sum_{i=1, i \neq s}^{n} \overline{N_{i}} \\
& +\int_{0}^{h \overline{\partial c_{s}}} d z-\overline{\chi_{s}}(h) \int_{0}^{h} \frac{\overline{\partial c_{d}}}{\partial t} d z .
\end{aligned}
$$

The constraining constituent or dry air source/sink correction term is split into two parts. The bracket in the left-hand side represents a self-correction factor of the specified constituent while the second term in the right-hand side represents a correction due to the net exchanges of the remaining dry air components. Both corrections become more important for larger mixing ratios. The significance of these corrections is best illustrated with the following special cases.

\subsection{1. $\mathrm{N}_{2}$}

Suppose one is interested in measuring the net ecosystem exchange of $\mathrm{N}_{2}$ due to nitrogen fixation or nitrification/denitrification processes. $\overline{\chi_{\mathrm{N}_{2}}} \approx 0.78 . \quad\left[\overline{N_{\mathrm{N}_{2}}}-\overline{N_{\mathrm{N}_{2}}}(1-\right.$ $0.78)] / \overline{N_{N_{2}}}=0.78$. Thus, ignoring the self-correction factor alone, a 78\% error will be committed. Neglecting net exchanges of other dry air components will result in even larger errors. Since the dry air source/sink correction term is dominated by the stoichiometric imbalance between $\overline{N_{\mathrm{CO}_{2}}}$ and $\overline{N_{\mathrm{O}_{2}}}$, it can be approximated with $\overline{\chi_{\mathrm{N}_{2}}}(1-k) \overline{N_{\mathrm{CO}_{2}}}$. Assuming $\overline{N_{\mathrm{CO}_{2}}}=-30 \mathrm{mmol} \mathrm{CO}_{2} \mathrm{~m}^{-2} \mathrm{~s}^{-1}$ and $k=1.6, \overline{\chi_{\mathrm{N}_{2}}}(1-k) \overline{N_{\mathrm{CO}_{2}}}=14 \mathrm{mmol} \mathrm{N}_{2} \mathrm{~m}^{-2} \mathrm{~s}^{-1}$. This is orders of magnitude larger than ecosystem $\mathrm{N}_{2}$ fluxes (Welsh et al., 2000). Thus, flux measurements of $\mathrm{N}_{2}$ made with the eddy covariance technique under the assumption of no net ecosystem source/sink of dry air would be meaningless. To measure the flux of $\mathrm{N}_{2}$, Eq. (12) must be applied.

\subsection{2. $\mathrm{CO}_{2}$}

Taking the stoichiometric relationship between $\overline{\mathrm{N}_{\mathrm{CO}_{2}}}$ and $\overline{\mathrm{N}_{2}}$ into consideration and ignoring contributions from other dry air components, Eq. (8) can be rewritten as

$\overline{N_{\mathrm{CO}_{2}}}\left[1-\overline{\chi_{\mathrm{CO}_{2}}}(h)(1-k)\right]=\left.\overline{c_{d}} \overline{w^{\prime} \chi_{\mathrm{CO}_{2}}^{\prime}}\right|_{h}+\int_{0}^{h} \overline{\frac{\partial c_{\mathrm{CO}_{2}}}{\partial t}} d z-\overline{\chi_{\mathrm{CO}_{2}}}(h) \int_{0}^{h} \overline{\frac{\partial c_{d}}{\partial t}} d z$.

Assuming $\overline{\chi \mathrm{CO}_{2}}(h)=4 \times 10^{-4} \quad(400 \mathrm{ppm}) \quad$ and $k=1.6$, $1-\overline{\chi_{\mathrm{CO}_{2}}}(h)(1-k)=1.00024 \approx 1$. Thus when measuring $\mathrm{CO}_{2}$ fluxes, the error caused by assuming a priori there is no net ecosystem source or sink of dry air does not exceed $0.024 \%$.

\subsection{3. ${ }^{13} \mathrm{CO}_{2}$}

Let $R_{13}^{\mathrm{N}} \mathrm{CO}_{2}=\overline{N_{13} \mathrm{CO}_{2}} / \overline{N_{\mathrm{CO}_{2}}}$, the carbon-13 fraction in the mean NEE of $\mathrm{CO}_{2}$. The ecosystem budget equation of ${ }^{13} \mathrm{CO}_{2}$ can be approximated as

$$
\begin{aligned}
\overline{N_{13} \mathrm{CO}_{2}}\left[1-\frac{\overline{\chi_{13} \mathrm{CO}_{2}}(h)(1-k)}{R_{13}^{\mathrm{N}} \mathrm{CO}_{2}}\right]= & \left.\overline{c_{d}} \overline{w^{\prime} \chi_{13}^{\prime} \mathrm{CO}_{2}}\right|_{h}+\int_{0}^{h} \frac{\overline{\partial c_{13} \mathrm{CO}_{2}}}{\partial t} d z \\
& -\overline{\chi_{13} \mathrm{CO}_{2}}(h) \int_{0}^{h} \frac{\overline{\partial c_{d}}}{\partial t} d z .
\end{aligned}
$$

$\overline{\chi_{13} \mathrm{CO}_{2}} \approx \overline{\mathrm{C}_{13} \mathrm{CO}_{2}} / \overline{\mathrm{C}_{12} \mathrm{CO}_{2}} \times \overline{\chi_{\mathrm{CO}_{2}}}=0.011145 \times 4 \times 10^{-4} \approx 4 \times 10^{-6}$, where 0.011145 is the current atmospheric ${ }^{13} \mathrm{C}$ to ${ }^{12} \mathrm{C}$ molar ratio (Keeling et al., 2010). Information on $R_{13}^{\mathrm{N}} \mathrm{CO}_{2}$ is very limited. But if it is assumed that the stable isotopic composition of soil respiration has a $\delta^{13} \mathrm{C}$ of $-30 \%$ (Kammer et al., 2011), then $R_{13 \mathrm{CO}_{2}}^{\mathrm{N}} \approx(1-0.03) \times 0.01124 \approx 0.01$, where 0.01124 is the standard carbon isotopic molar ratio in the Pee Dee Belemnite (PDB; Craig, 1957). If only photosynthesis and C3 plants are considered, $R_{13}^{\mathrm{N}} \mathrm{CO}_{2}=0.011145 /(1+0.02) \approx 0.01$, where 0.02 is a typical photosynthetic discrimination for C3 plants ( $\Delta=20 \%$, Farquhar et al., 1989). Therefore, one might assume that ecosystems have a typical $R_{13}^{\mathrm{N}} \mathrm{CO}_{2}$ on the order of 0.01 , and $1-\overline{\chi_{13} \mathrm{CO}_{2}}(h)(1-k) / R_{13}^{\mathrm{N}} \mathrm{CO}_{2} \approx 1.00024 \approx 1$. Thus we can conclude that the assumption of no net ecosystem source or sink of dry air is also valid for measuring carbon isotopic fluxes.

\subsection{4. $\mathrm{O}_{2}$}

An interesting situation arises when one attempts to measure $\mathrm{O}_{2}$ flux instead of $\mathrm{CO}_{2}$ flux. Using $\overline{N_{d}} \approx(1-(1 / k)) \overline{N_{\mathrm{O}_{2}}}$, Eq. (8) becomes $\overline{N_{\mathrm{O}_{2}}}\left[1-\overline{\chi_{\mathrm{O}_{2}}}(h)\left(1-\frac{1}{k}\right)\right]=\left.\overline{c_{d}} \overline{w^{\prime} \chi_{\mathrm{O}_{2}}^{\prime}}\right|_{h}+\int_{0}^{h} \overline{\frac{\partial c_{\mathrm{O}_{2}}}{\partial t}} d z-\overline{\chi_{\mathrm{O}_{2}}}(h) \int_{0}^{h} \overline{\frac{\partial c_{d}}{\partial t}} d z$.

$\overline{\chi_{\mathrm{O}_{2}}} \approx 0.21$. For $k=1.6,1-\overline{\chi_{\mathrm{O}_{2}}}(1-(1 / k)) \approx 0.9$. Thus, a $10 \%$ error will be introduced by setting $\overline{N_{d}}=0$. To measure the flux of $\mathrm{O}_{2}$, the value of $k$ is needed.

\subsection{5. $\mathrm{H}_{2} \mathrm{O}$}

The dry air source/sink correction term for water vapor flux is approximately given by $\overline{\chi_{\mathrm{H}_{2} \mathrm{O}}}(1-k) \overline{\mathrm{N}_{\mathrm{CO}_{2}}}$. For a relative humidity of $100 \%$ at an air temperature of $25^{\circ} \mathrm{C}, \overline{\chi_{\mathrm{H}_{2} \mathrm{O}}} \approx 0.03$. Assuming a peak daytime $\overline{N_{\mathrm{CO}_{2}}}=-30 \mathrm{mmol} \mathrm{CO}_{2} \mathrm{~m}^{-2} \mathrm{~s}^{-1}$ and $k=1.6$, the correction is about $0.54 \mu \mathrm{mol} \mathrm{H}_{2} \mathrm{O} \mathrm{m}^{-2} \mathrm{~s}^{-1}=0.00054 \mathrm{mmol} \mathrm{H}_{2} \mathrm{O} \mathrm{m}^{-2} \mathrm{~s}^{-1}$. Typical water vapor flux is on the order of $1 \mathrm{mmol} \mathrm{H}_{2} \mathrm{O} \mathrm{m}^{-2} \mathrm{~s}^{-1}$. Thus, assuming $\overline{N_{d}}=0$ causes errors $<0.05 \%$ for water vapor flux measurements.

An important insight from these special case analyses is that, with the information typically available, the contemporary eddy covariance technique cannot measure the flux of every atmospheric constituent even when a fast response gas analyzer with sufficient accuracy is available. For example, it cannot be used to determine fluxes of $\mathrm{N}_{2}$ and $\mathrm{O}_{2}$ unless the fluxes of other non-water vapor gases are known and the ecosystem $\mathrm{O}_{2}: \mathrm{CO}_{2}$ molar exchange ratio is given. As a general rule, the assumption of no net ecosystem source or sink of dry air can be made for measuring fluxes of an atmospheric constituent $s$ only if the following condition is true:

$\left|\overline{N_{s}}\right| \gg\left|\overline{\chi_{s}}\right|\left|\overline{N_{\mathrm{CO}_{2}}}\right|$.

When this condition holds, the NEE of $s$ for horizontally homogeneous air flows can be calculated with

$\overline{N_{s}}=\left.\overline{c_{d}} \overline{w^{\prime} \chi_{s}^{\prime}}\right|_{h}+\int_{0}^{h} \overline{\frac{\partial c_{s}}{\partial t}} d z-\overline{\chi_{s}}(h) \int_{0}^{h} \frac{\overline{\partial c_{d}}}{\partial t} d z$,

for a closed-path system, or with

$\overline{N_{s}}=\left.\overline{w^{\prime} c_{s}^{\prime}}\right|_{h}+\overline{\chi_{s}}\left[\overline{w^{\prime} c_{v}^{\prime}}+\bar{c} \frac{\overline{w^{\prime} T^{\prime}}}{\bar{T}}\right]_{h}+\int_{0}^{h} \overline{\frac{\partial c_{s}}{\partial t}} d z-\overline{\chi_{s}}(h) \int_{0}^{h} \frac{\partial c_{d}}{\partial t} d z$,

for an open-path system. These two equations are identical to those in Leuning $(2004,2007)$ and Lee and Massman (2011) who for their purpose of discussion assumed a priori there is no net ecosystem source or sink of dry air.

\subsection{The assumption of steady-state conditions of WPL 1980}

A central concept in WPL 1980 was that 'there is no source or sink of (dry) air at the ground'. This concept was implemented by making the vertical flux of dry air at the EC measurement plane to be zero (Eqn. (11) in WPL 1980). The WPL 1980 treatment is only valid 
for steady-state conditions. For non-steady state conditions, it will be necessary to modify the term for the change in storage in order to avoid biases in the estimated NEE. Note that the eddy flux term derived by WPL 1980 is still correct for non-steady state conditions (Leuning, 2007; also see Appendix A). Horizontally homogenous, non-steady flows have been addressed in Leuning (2004, 2007), Kowalski and Serrano-Ortiz (2007) and Lee and Massman (2011). Later, we will use measurements to demonstrate the magnitude of the change in storage term when the steady-state theory is replaced with the more general non-steady state theory.

\subsection{Approximations to the effective change in storage}

To compute the effective change in storage

$\int_{0}^{h} \frac{\overline{\partial c_{s}}}{\partial t} d z-\overline{\chi_{s}}(h) \int_{0}^{h} \frac{\overline{\partial c_{d}}}{\partial t} d z$

the molar density profiles of both $s$ and dry air must be known. Trace gas profiles are typically measured by sampling air at multiple levels, drying the air and then passing it through a closed-path gas analyzer. Mixing ratios are conserved when temperatures $(T)$ and pressures $(P)$ at the air sampling height differ from those in the gas analyzer but the same is not true when measuring densities. Measurement of density profiles thus requires additional knowledge of $T$ and $P$ at each sampling height, whereas both density and mixing ratio measurements require knowledge of $T$ and $P$ in the gas analyzer itself. Therefore it will be convenient if the effective change in storage can be calculated directly from mixing ratio profiles.

The total change in storage of $s$ can be expressed in mixing ratio through linearization:

$\int_{0}^{h} \frac{\overline{\partial c_{s}}}{\partial t} d z=\int_{0}^{h} \frac{\overline{\partial \chi_{s} c_{d}}}{\partial t} d z=\int_{0}^{h} \overline{\chi_{s}}(z) \frac{\overline{\partial c_{d}}}{\partial t} d z+\int_{0}^{h} \overline{c_{d}}(z) \overline{\frac{\partial \chi_{s}}{\partial t}} d z,(17)$ which leads to an equivalent expression for the effective change in storage

$$
\begin{aligned}
\int_{0}^{h} \overline{\frac{\partial c_{s}}{\partial t}} d z-\overline{\chi_{s}}(h) \int_{0}^{h} \frac{\overline{\partial c_{d}}}{\partial t} d z= & \int_{0}^{h} \overline{c_{d}}(z) \frac{\overline{\partial \chi_{s}}}{\partial t} d z+\int_{0}^{h}\left[\overline{\chi_{s}}(z)\right. \\
& \left.-\overline{\chi_{s}}(h)\right] \frac{\partial c_{d}}{\partial t} d z .
\end{aligned}
$$

Both $\overline{\partial \chi_{s}} / \partial t$ and $\overline{\partial c_{d}} / \partial t$ are functions of height. Note that the second term in the right-hand side of Eq. (18) depends on the difference in mixing ratio at heights $z$ and $h$ and it becomes negligible for well mixed conditions, irrespective of the magnitude of $\overline{\partial c_{d}} / \partial t$.

Leuning (2007) simplified Eq. (18) by implicitly introducing the following approximations:

$\int_{0}^{h} \overline{c_{d}}(z) \overline{\frac{\partial \chi_{s}}{\partial t}} d z \approx \overline{c_{d}}(h) \int_{0}^{h} \frac{\overline{\partial \chi_{s}}}{\partial t} d z$

and

$\int_{0}^{h} \overline{\chi_{s}}(z) \frac{\overline{\partial c_{d}}}{\partial t} d z \approx \overline{\chi_{s}}(h) \int_{0}^{h} \frac{\overline{\partial c_{d}}}{\partial t} d z$

to yield

$\int_{0}^{h} \frac{\partial c_{s}}{\partial t} d z-\overline{\chi_{s}}(h) \int_{0}^{h} \frac{\overline{\partial c_{d}}}{\partial t} d z \approx \overline{c_{d}}(h) \int_{0}^{h} \overline{\frac{\partial \chi_{s}}{\partial t}} d z$.

Consequently $\overline{N_{S}}$ is reduced, elegantly, to

$\overline{N_{s}} \approx \overline{c_{d}}(h)\left(\left.\overline{w^{\prime} \chi_{s}^{\prime}}\right|_{h}+\int_{0}^{h} \overline{\frac{\partial \chi_{s}}{\partial t}} d z\right)$.
Eq. (22) is simply the conservation equation for the quantity 'mixing ratio' with the mean molar density of dry air at $h$ as a conversion factor. This result arises because part of the total vertical flux of $s$ at $h$ is equal and opposite to a change in storage that is not caused by ecosystem exchange but by air expansion and contraction below $h$ as a result of changes in $T$ and $P$. Under fully mixed conditions, these two components in the effective change in storage term cancel each other and do not appear in the $\chi_{s}$-based expression of $\overline{N_{S}}$ because $\chi_{s}$ is conserved to varying $T$ and $P$.

Eq. (22) still requires a vertical profile of $\chi_{s}$. It is worthy to investigate whether it can be simplified further by assuming the mean change in time of $\chi_{s}$ does not depend on height, which results in

$\left.\overline{N_{s}} \approx \overline{c_{d}}\left(\overline{w^{\prime} \chi_{s}^{\prime}}+\overline{\frac{\partial \chi_{s}}{\partial t}} h\right)\right|_{h}$

With Eq. (23), only a single-height mixing ratio measurement is needed. The simple method of estimating changes in storage from single-height, most frequently, tower-top measurements has been used widely by the flux community (Amiro, 2001; Carrara et al., 2003; Greco and Baldocchi, 1996; Hollinger et al., 1994; Kolari et al., 2004; Pilegaard et al., 2001).

When the eddy covariance instrumentation measures densities rather than mixing ratios, the WPL equivalents of Eqs. (22) and (23) are, respectively:

$\left.\overline{N_{s}} \approx \overline{w^{\prime} c_{s}^{\prime}}\right|_{h}+\overline{\chi_{s}}\left[\overline{w^{\prime} c_{v}^{\prime}}+\bar{c} \frac{\overline{w^{\prime} T^{\prime}}}{\bar{T}}\right]_{h}+\overline{c_{d}}(h) \int_{0}^{h} \frac{\overline{\partial \chi_{s}}}{\partial t} d z$

and

$\left.\overline{N_{s}} \approx \overline{w^{\prime} c_{s}^{\prime}}\right|_{h}+\overline{\chi_{s}}\left[\overline{w^{\prime} c_{v}^{\prime}}+\bar{c} \overline{\frac{w^{\prime} T^{\prime}}{\bar{T}}}\right]_{h}+\left.\overline{c_{d}} \frac{\overline{\partial \chi_{s}}}{\partial t}\right|_{h} h$.

In Section 4, we will show that Eqs. (22) and (24) are highly accurate while Eqs. (23) and (25) can cause considerable error. This indicates that the operators of time derivative and vertical integration on mixing ratio are not commutable.

\subsection{The approximation to horizontal advection in the case of non-homogeneous mass fluxes}

In Appendix A, it is shown that the horizontal advection term in the case of non-homogeneous mass fluxes can be potentially simplified by introducing 3D versions of the approximations Eqs. (19) and (20). The simplified horizontal advection term is

$$
\int_{0}^{h} \nabla_{H} \cdot\left(\overline{\mathbf{u} c_{d}} \overline{\chi_{s}}+\overline{c_{d}} \overline{\mathbf{u}^{\prime} \chi_{s}^{\prime}}\right) d z-\overline{\chi_{s}}(h) \int_{0}^{h} \nabla_{H} \cdot\left(\overline{\mathbf{u} c_{d}}\right) d z \approx \overline{c_{d}}(z) \int_{0}^{h} \nabla_{H} \cdot\left(\overline{\overline{\mathbf{u}^{\prime} \chi_{s}^{\prime}}}\right) d z
$$

Combining this approximation with the approximated effective change in storage (Eq. (21)) and the assumption of no net ecosystem source/sink of dry air, the general FQEC Eq. (10) is reduced to

$\overline{N_{s}} \approx \overline{c_{d}}(h)\left\{\left.\overline{w^{\prime} \chi_{s}^{\prime}}\right|_{h}+\int_{0}^{h} \nabla_{H} \cdot\left(\overline{\mathbf{u}^{\prime} \chi_{s}^{\prime}}\right) d z+\int_{0}^{h} \frac{\overline{\partial \chi_{s}}}{\partial t} d z\right\}$.

We do not intend to evaluate the accuracy of Eq. (27) in this current study. It is presented here as something of interest for future investigation. 


\section{Observational evaluation of approximations to the fundamental equation of eddy covariance for horizontally homogeneous mass fluxes}

\subsection{Tasks of evaluation and assumptions adopted}

We used observations to assess errors introduced by approximations to the FQEC for horizontally homogeneous mass fluxes. Two tasks were performed. First, we determined the magnitude of the dry air storage adjustment term $-\overline{\chi_{s}}(h) \int_{0}^{h}\left(\overline{\partial c_{d}} / \partial t\right) d z$. Second, we evaluated the relative errors caused by estimating the effective change in storage term (Eq. (16)) with the approximation of Eq. (21) using a measured mixing ratio profile or with the approximation of Eq. (23) using a single measurement at the height of the EC instrumentation. The relative errors were given by

$\varepsilon_{1}=100 \times \frac{\int_{0}^{h}\left[\overline{c_{d}}(z)-\overline{c_{d}}(h)\right]\left(\overline{\partial \chi_{s}} / \partial t\right) d z+\int_{0}^{h}\left[\overline{\chi_{s}}(z)-\overline{\chi_{s}}(h)\right]\left(\overline{\partial c_{d}} / \partial t\right) d z}{\int_{0}^{h} \overline{c_{d}}(z)\left(\overline{\partial \chi_{s}} / \partial t\right) d z+\int_{0}^{h}\left[\overline{\chi_{s}}(z)-\overline{\chi_{s}}(h)\right]\left(\overline{\partial c_{d}} / \partial t\right) d z}$

for profile, and

$\varepsilon_{2}=100 \times \frac{\int_{0}^{h} \overline{c_{d}}(z)\left(\overline{\partial \chi_{s}} / \partial t\right) d z-\overline{c_{d}}(h)\left(\overline{\partial \chi_{s}}(h) / \partial t\right) h+\int_{0}^{h}\left[\overline{\chi_{s}}(z)-\overline{\chi_{s}}(h)\right]\left(\overline{\partial c_{d}} / \partial t\right) d z}{\int_{0}^{h} \overline{c_{d}}(z)\left(\overline{\partial \chi_{s}} / \partial t\right) d z+\int_{0}^{h}\left[\overline{\chi_{s}}(z)-\overline{\chi_{s}}(h)\right]\left(\overline{\partial c_{d}} / \partial t\right) d z}$

for single measurement. The fluxes were computed by assuming no net ecosystem exchange of dry air (i.e., $\overline{N_{d}}=0$ ) and no horizontal advection.

\subsection{Study site and measurements}

Measurements in 2007 from the Missouri Ozark AmeriFlux (MOFLUX) site were used. The MOFLUX site is located within the University of Missouri's Baskett Wildlife Research and Education Area (BREA) in central Missouri, USA $\left(38^{\circ} 40^{\prime} \mathrm{N}, 92^{\circ} 12^{\prime} \mathrm{W}\right)$. The site is occupied by a mixed forest of mostly deciduous species dominated by oaks (Quercus spp.) with the evergreen species eastern red cedar (Juniperus virginiana L.) as a minor component. The canopy height is about $20 \mathrm{~m}$. Detailed site information can be found elsewhere (Pallardy et al., 1988; Gu et al., 2006). Under unstressed conditions during mid growing season, $\mathrm{CO}_{2}$ fluxes generally fall into the range of -30 to $5 \mu \mathrm{mol} \mathrm{m}^{-2} \mathrm{~s}^{-1}$ (uptake negative, emission positive) and water vapor fluxes $0-10 \mathrm{mmol} \mathrm{m}^{-2} \mathrm{~s}^{-1}$ (Gu et al., 2006, 2007; Yang et al., 2010). In addition to typical EC and meteorological instrumentation, MOFLUX is equipped with a $\mathrm{CO}_{2} / \mathrm{H}_{2} \mathrm{O}$ mole fraction profile system (Table 1 ) and an air temperature/humidity profile system which are attached to the $32 \mathrm{~m}$ flux tower (Yang et al., 2007). The $\mathrm{CO}_{2} / \mathrm{H}_{2} \mathrm{O}$ profile system measures $\mathrm{CO}_{2}$ and $\mathrm{H}_{2} \mathrm{O}$ mole fractions at 12 levels $(0.15,0.30,0.61,0.91,1.52,3.05,6.10,9.14$, $12.19,16.76,22.86$, and $30.48 \mathrm{~m}$ ) with a single $\mathrm{LI}-7000 \mathrm{CO}_{2} / \mathrm{H}_{2} \mathrm{O}$ gas analyzer (LI-COR, Inc., Lincoln, Nebraska, USA). Air is drawn sequentially from the 12 heights through Teflon tubing to the analyzer housed in a shelter near the base of the flux tower. One measurement cycle lasts $12 \mathrm{~min}$. The temperature/humidity profile system measures air temperature and humidity at 8 levels $(0.61,1.52,6.10$, $9.14,12.19,16.76,22.86$, and $30.48 \mathrm{~m}$ ) with 8 Vaisala HMP45 C temperature/RH probes. Data from these two profiles plus barometric pressure measurements at the top of the tower allow the calculation of ambient molar densities of dry air, $\mathrm{CO}_{2}$ and $\mathrm{H}_{2} \mathrm{O}$ and gas mixing ratio relative to dry air at different heights.

Because the $\mathrm{CO}_{2} / \mathrm{H}_{2} \mathrm{O}$ profile and the temperature/RH profile did not match each other exactly in measurement time and height, a bivariate mesh grid cubic spline with a moving window of one day was used to interpolate temperatures from the temperature/ $\mathrm{RH}$ profile to the desired heights and times of the $\mathrm{CO}_{2} / \mathrm{H}_{2} \mathrm{O}$ profile. The interpolated temperatures were then used to convert $\mathrm{CO}_{2}$ and
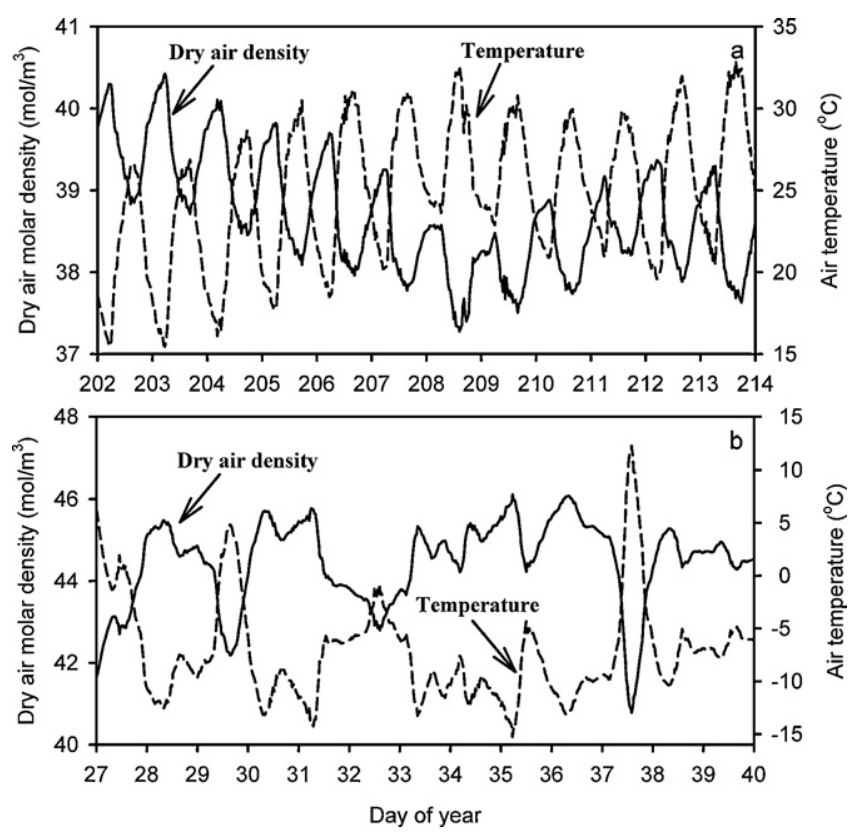

Fig. 1. Diurnal variations in the dry air molar density and air temperature during a summer period (a) and a winter period (b) of 2007 at the Missouri Ozark AmeriFlux site.

$\mathrm{H}_{2} \mathrm{O}$ mole fractions to ambient molar densities using the ideal gas law. The ideal gas law was applied again to calculate dry air molar densities from the converted $\mathrm{H}_{2} \mathrm{O}$ molar densities, interpolated temperatures, and atmospheric pressure. The atmospheric pressure was interpolated from measurements at the top of the tower to any desired height with the hydrostatic equation. A cubic spline similar to that for temperature was then used to interpolate dry air molar densities and $\mathrm{CO}_{2}$ and $\mathrm{H}_{2} \mathrm{O}$ molar densities and mixing ratios to regular half-hourly time intervals to match with eddy flux measurements. Rates of change in storage of dry air, $\mathrm{CO}_{2}$ and $\mathrm{H}_{2} \mathrm{O}$ were calculated by integrating the obtained profiles of dry air, $\mathrm{CO}_{2}$ and $\mathrm{H}_{2} \mathrm{O}$ molar densities, respectively. Finally, the dry air storage adjustment, the effective change in storage and its approximations were calculated for fluxes of $\mathrm{CO}_{2}$ and $\mathrm{H}_{2} \mathrm{O}$.

\subsection{Results of observational evaluation}

\subsubsection{The magnitude of the dry air storage adjustment term}

The dry air density showed clear diurnal variations, implying systematic positive and negative fluxes of dry air through the EC measurement plane, depending on the sign of $\partial c_{d} / \partial d t$ (Eq. (16)). Typical temporal patterns were demonstrated for a summer period (Fig. 1a) and a winter period (Fig. 1b) at the top profile measurement height of about $30 \mathrm{~m}$ ( $2 \mathrm{~m}$ below the EC measurement level). The magnitude of diurnal variation was nearly $2 \mathrm{~mol} \mathrm{~m}^{-3}$ during summer and more than twice as much during winter. In the morning as the surface heating began, the dry air density decreased steadily, reached a minimum at the temperature maximum and then increased afterwards. It peaked around the daily temperature minimum. The dry air density also varied beyond the diurnal time scales with the daily cycles superimposed on the longer trends.

As could be inferred from the diurnal variations in dry air densities, the total mass of dry air below the EC measurement plane in a column of unit ground area (storage in dry air) was not constant. Fig. 2a and b showed the time series of the rate of change in storage of dry air for the corresponding periods in Fig. 1a and b, respectively. The rate of change in storage of dry air ranged from $-5 \mathrm{mmol} \mathrm{m}^{-2} \mathrm{~s}^{-1}$ during the day to $5 \mathrm{mmol} \mathrm{m}^{-2} \mathrm{~s}^{-1}$ at night for the summer period (Fig. 2a) and from -6 to $6 \mathrm{mmol} \mathrm{m}^{-2} \mathrm{~s}^{-1}$ for the 
Table 1

A comparison of profile design for estimating change in storage between this and some previous studies.

\begin{tabular}{|c|c|c|c|}
\hline References & Canopy height $(\mathrm{m})$ & EC height (m) & Profile levels (below EC) \\
\hline Anthoni et al. (1999) & 33 & 47 & $4(1,8,31$, and $46 \mathrm{~m})$ \\
\hline Hollinger et al. (1994) & 30 & 36 & $4(2,17,23$, and $30 \mathrm{~m})$ \\
\hline Knohl et al. (2003) & 33 & 44 & $9(0.1,0.3,1,2,5,10,20,30$, and $40 \mathrm{~m})$ \\
\hline Priante-Filho et al. (2004) & 29 & 42 & $5(1,4,12,20$, and $28 \mathrm{~m})$ \\
\hline Vourlitis et al. (2001) & 29 & 42 & $5(1,4,12,20$, and $28 \mathrm{~m})$ \\
\hline Yang et al. (1999) & 22 & 40 & $8(0.8,2.3,9.5,15.7,18.8,21.9,25$, and $34.2 \mathrm{~m})$ \\
\hline This study & 20 & 32 & $12(0.15,0.3,0.61,0.91,1.52,3.05,6.1,9.14,12.19,16.76,22.86$ and $30.48 \mathrm{~m})$ \\
\hline
\end{tabular}

winter period (Fig. 2b). Assuming no horizontal advection, a negative change in storage of dry air implied a positive flux of dry air (upwards) across the EC measurement plane while a positive change in storage indicated downwards flow of dry air.

The dry air storage term of $s$ that accounts for positive or negative fluxes of dry air (the dry air storage adjustment) was shown in Fig. 3 for the flux of $\mathrm{CO}_{2}$ and Fig. 4 for water vapor. Also shown in these two figures were the percentages of the dry air storage adjustments relative to the corresponding eddy fluxes.

The dry air storage adjustment tended to be positive during the day and negative at night and larger in the morning than in the afternoon for both $\mathrm{CO}_{2}$ and water vapor (Figs. 3 and 4 ). For $\mathrm{CO}_{2}$, the adjustment generally fell into the range of -2 to $2 \mu \mathrm{mol} \mathrm{m}^{-2} \mathrm{~s}^{-1}$ although values exceeding this range were observed, particularly during winter time. Around midday during summer when the eddy flux was large, the dry air storage adjustment for the flux of $\mathrm{CO}_{2}$ was about $10 \%$ of the eddy flux $\left(\mathrm{CO}_{2}\right.$ eddy flux was about $-20 \mu \mathrm{mol} \mathrm{m}^{-2} \mathrm{~s}^{-1}$ during a typical summer day, data not shown). However, at night and during day-night transitional periods, the adjustment was occasionally much larger than the eddy flux itself (Fig. 3a). In winter (Fig. 3b), the adjustment was of similar or larger magnitude than that of the eddy flux and at times dominated over the eddy flux at night or during transitional periods.

The temporal pattern of the dry air storage adjustment for flux of water vapor was the same as that of $\mathrm{CO}_{2}$ as both are proportional to the rate of change in storage of dry air below the EC measurement

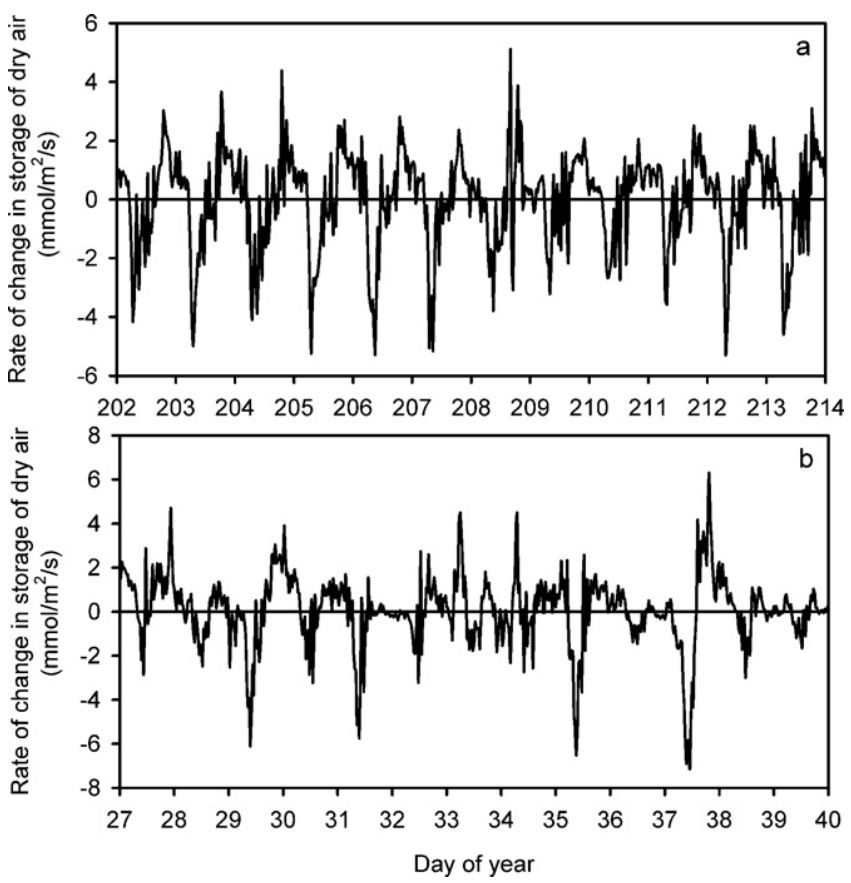

Fig. 2. Diurnal variations in the rate of change in storage of dry air below the eddy covariance measurement plane during a summer period (a) and a winter period (b) of 2007 at the Missouri Ozark AmeriFlux site.
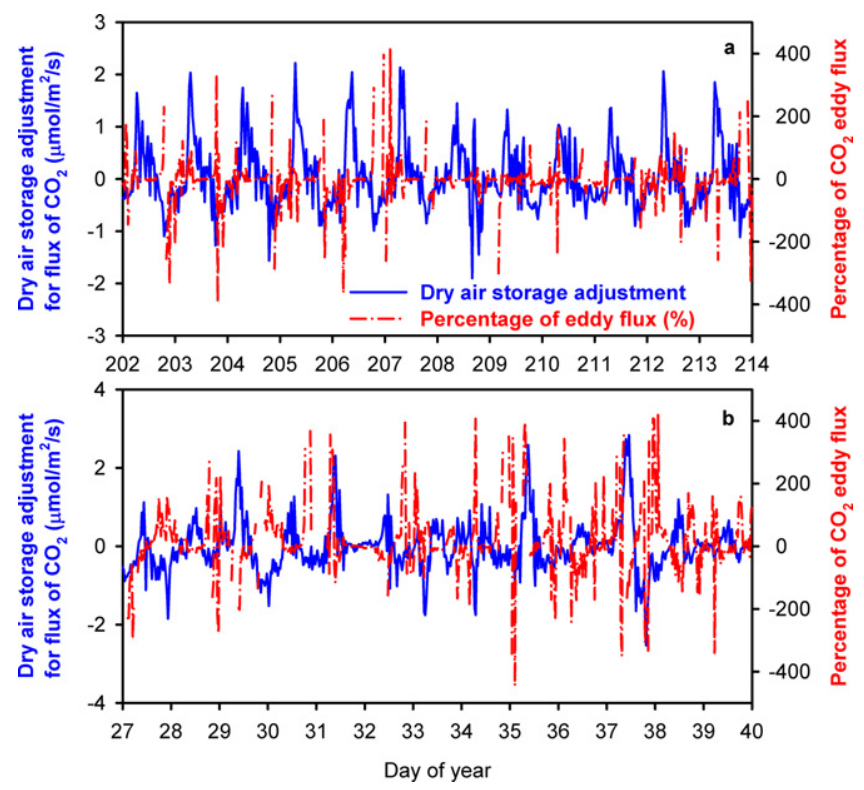

Fig. 3. Diurnal variations in the dry air storage adjustment for flux (solid blue curves) and the adjustment as a percentage of the eddy flux (dash-dot red curves) of $\mathrm{CO}_{2}$ during a summer period (a) and a winter period (b) of 2007 at the Missouri Ozark AmeriFlux site. (For interpretation of the references to color in this figure legend, the reader is referred to the web version of the article.)

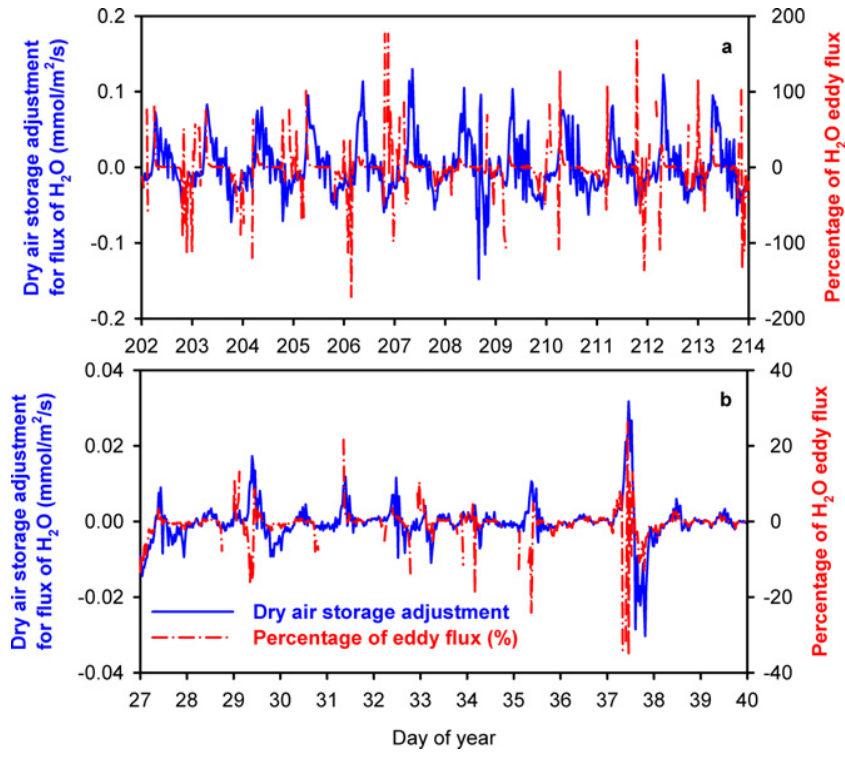

Fig. 4. Diurnal variations in the dry air storage adjustment for flux (solid blue curves) and the adjustment as a percentage of the eddy flux (dash-dot red curves) of water vapor during a summer period (a) and a winter period (b) of 2007 at the Missour Ozark Ameriflux site. (For interpretation of the references to color in this figure legend, the reader is referred to the web version of the article.) 

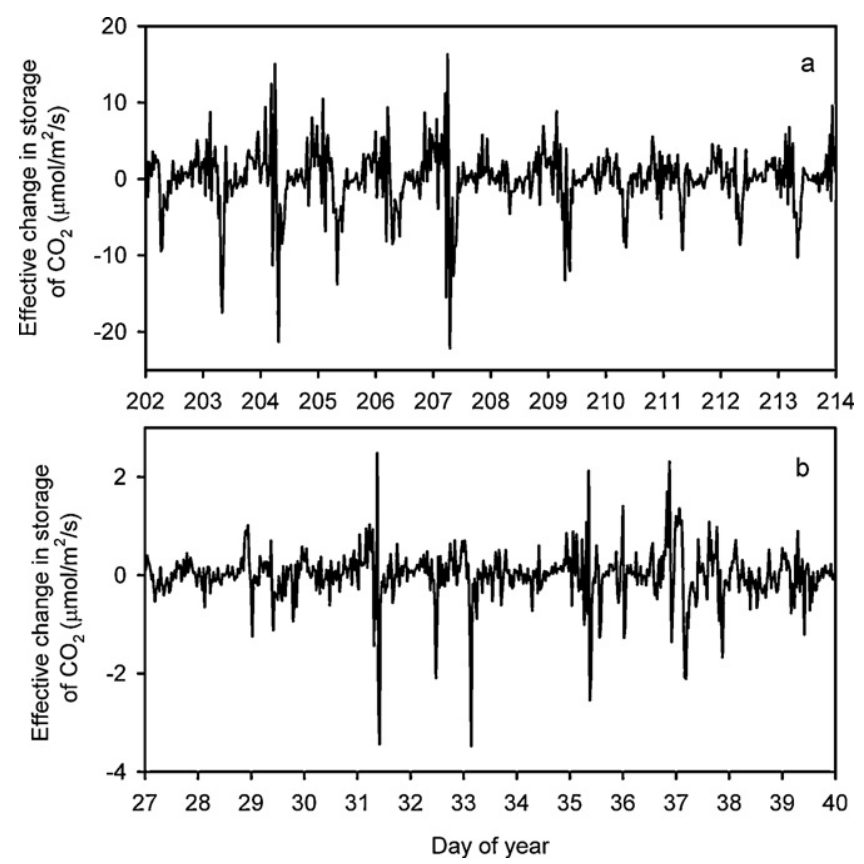

Fig. 5. Temporal variations in the exactly-computed effective change in storage of $\mathrm{CO}_{2}$ during a summer period (a) and a winter period (b) of 2007 at the Missouri Ozark AmeriFlux site.

plane. The adjustment ranged from -0.15 to $0.15 \mathrm{mmol} \mathrm{m}^{-2} \mathrm{~s}^{-1}$ during summer (Fig. 4a) and from -0.03 to $0.03 \mathrm{mmol} \mathrm{m}^{-2} \mathrm{~s}^{-1}$ during winter (Fig. 4b). This magnitude of adjustment was about $2 \%$ of the vertical eddy flux of water vapor during peak transpiration periods. But at night or during transitional periods, the adjustment was comparable to or even larger than the eddy flux. Because it was positive during the day, the adjustment should increase the measured evapotranspiration and latent heat flux somewhat.

\subsubsection{The magnitude of the effective change in storage computed exactly}

The effective change in storage (Eq. (16)) computed exactly from the vertical profile systems at MOFLUX was shown in Fig. 5 for $\mathrm{CO}_{2}$ and Fig. 6 for water vapor for selected representative periods. The effective change in storage of $\mathrm{CO}_{2}$ varied diurnally with a range from -20 to $20 \mu \mathrm{mol} \mathrm{m}^{-2} \mathrm{~s}^{-1}$ in summer (Fig. 5a) and from -3 to $3 \mu \mathrm{mol} \mathrm{m}^{-2} \mathrm{~s}^{-1}$ in winter (Fig. 5b). The effective change in storage of water vapor also showed diurnal variations with a range from -2 to $2 \mathrm{mmol} \mathrm{m}^{-2} \mathrm{~s}^{-1}$ in summer (Fig. 6a) and from -0.6 to $0.6 \mathrm{mmol} \mathrm{m}^{-2} \mathrm{~s}^{-1}$ in winter (Fig. 6b). These large ranges had the same magnitudes as the vertical eddy fluxes in corresponding time periods. Thus clearly it was important to account for the effective change in storage in flux measurements.

\subsubsection{The errors of the approximations to the effective change in storage}

Fig. 7 showed the probability density distributions of the relative errors of approximating the effective change in storage of $\mathrm{CO}_{2}$ and water vapor with a multi-height mixing ratio profile $\left(\varepsilon_{1}, a\right.$ and $b$ ) or with a single tower-top mixing ratio measurement $\left(\varepsilon_{2}, c\right.$ and d). When the 12-height mixing ratio profile was used, the distributions were symmetrical with $97 \%$ of the values of the estimated effective change in storage of $\mathrm{CO}_{2}$ having a relative error between $-5 \%$ and $+5 \%$ (Fig. $7 a$ ) and $94 \%$ for water vapor (Fig. 7 b). Thus Eq. (21) provides an excellent approximation to the effective change in storage (Eq. (16)) when measurements at multiple heights are used to characterize the mixing ratio profile. In contrast, when a single mixing ratio at the tower top was used to estimate the storage term,
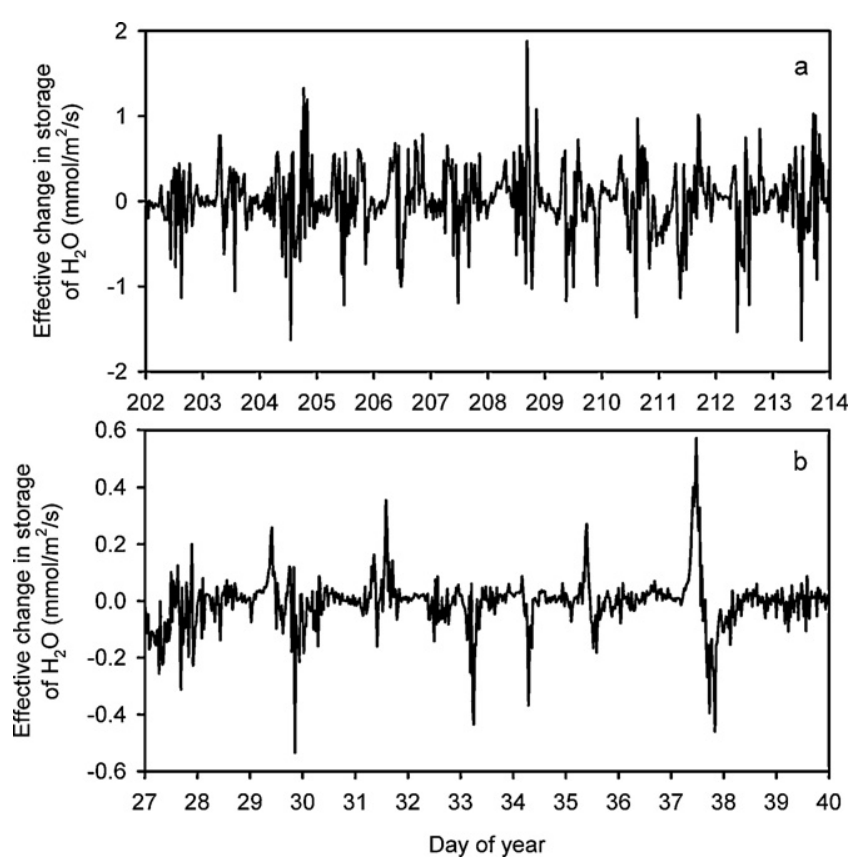

Fig. 6. Temporal variations in the exactly-computed effective change in storage of water vapor during a summer period (a) and a winter period (b) of 2007 at the Missouri Ozark AmeriFlux site.

the distributions were strongly positively skewed (Fig. 7c and d), indicating the tower-top approximation underestimated changes in storage. Furthermore, only $5 \%(6 \%)$ of the values had a relative error between $-5 \%$ and $+5 \%$ for $\mathrm{CO}_{2}$ (water vapor).

We note that previous researchers have compared (Carrara et al., 2003; Hollinger et al., 1994; Knohl et al., 2003; Vourlitis et al., 2001; Yang et al., 1999) or used interchangeably (Anthoni et al., 1999; Knohl et al., 2003; Priante-Filho et al., 2004; Vourlitis et al., 2001 ) estimates of change in storage based on tower-top and profile measurements. Profile designs varied considerably in these studies (Table 1). An earlier investigation from MOFLUX found that an adequately designed profile for change in storage should consider both the number and configuration of measurement heights (Yang et al., 2007). At the MOFLUX site, change in storage tended to be dominated by variations near the ground, particularly when the atmosphere was stratified, and therefore the lower section was measured densely (Table 1 ). If a profile is not designed adequately, particularly if the sections near sources or sinks are not sampled with sufficient density, it may give an estimate of change in storage that is not much different from that based on tower-top measurements. Difference in profile design (Table 1) may explain why our finding was inconsistent with that of some previous studies with respect to the adequacy in using single tower-top measurements for estimating change in storage.

\section{Discussion}

Using the conservation of mass of dry air as a constraint in flux measurements is an important feature of the contemporary eddy covariance technique. However, the eddy covariance theory itself can be formulated independent of dry air. A fundamental equation of eddy covariance has been derived that allows the net ecosystem exchange of a specified atmospheric constituent to be measured with the constraint of the conservation of mass of any other atmospheric constituent. The basis upon which the flux measurements are ultimately constrained is that the mean bulk velocity must be identical for each and every atmospheric constituent, no matter what processes cause this velocity. It is neither necessary nor 

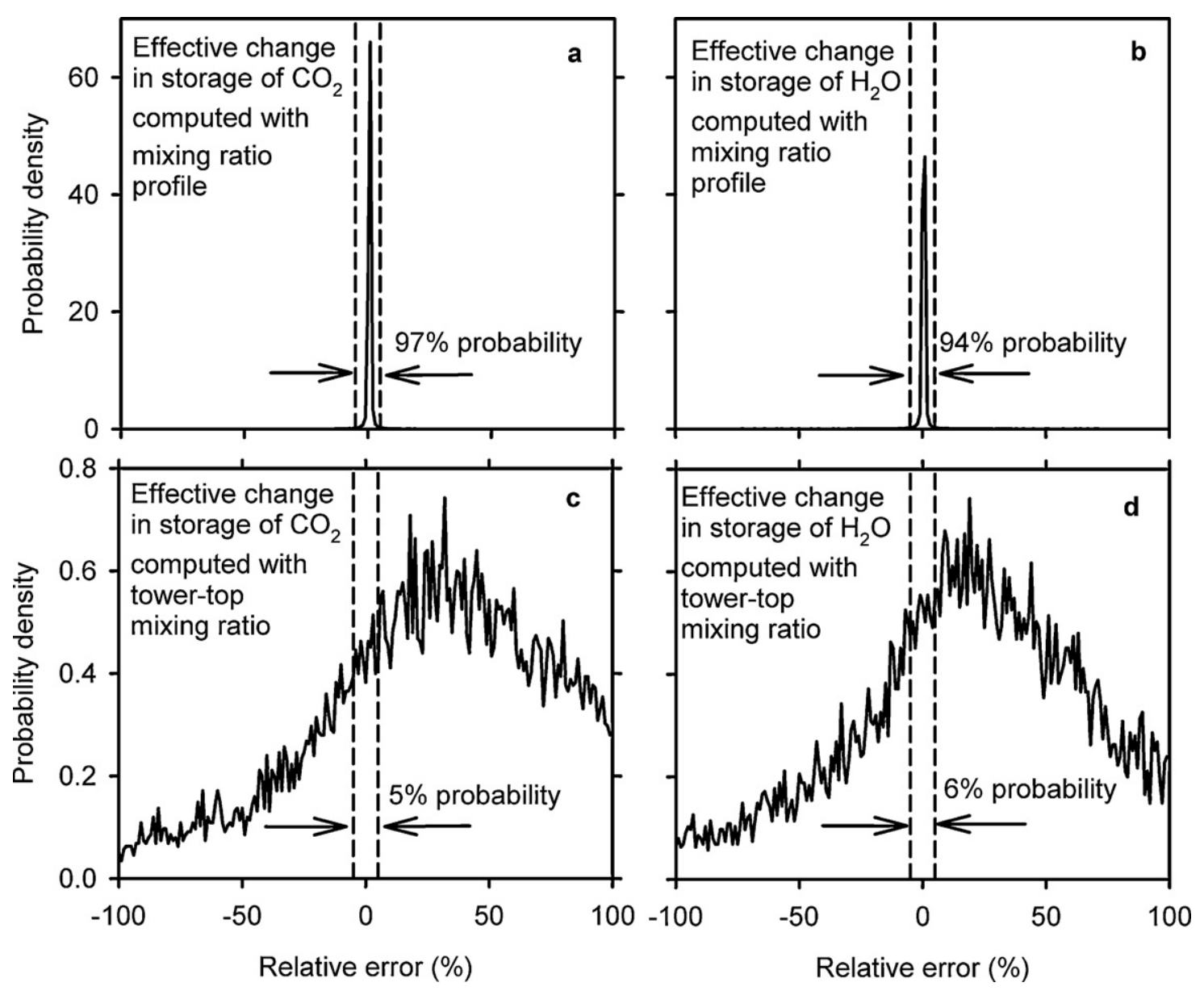

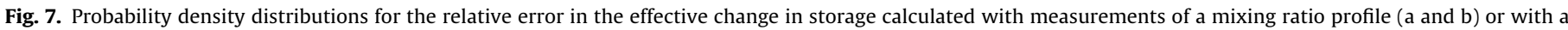

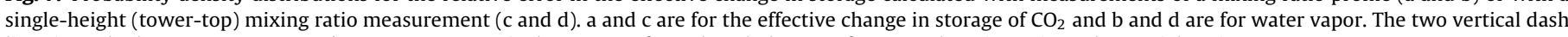
lines in each plot represent $-5 \%$ and $+5 \%$ errors respectively. Data are from the whole year of 2007 at the Missouri Ozark AmeriFlux site.

feasible to separate the mean bulk velocity into components that result from individual processes. The application of the conservation of dry air is a special case of the fundamental equation of eddy covariance and is convenient from an instrumentation point of view. However $\mathrm{N}_{2}$ or argon may also be used.

When the conservation of mass of dry air is used as a constraint, the net ecosystem exchange of a specified atmospheric constituent $s$ for horizontally homogeneous mass fluxes can be measured using any of the following equations:

$\overline{N_{s}}=\left.\overline{c_{d}} \overline{w^{\prime} \chi_{s}^{\prime}}\right|_{h}+\int_{0}^{h} \overline{c_{d}}(z) \frac{\partial \overline{\chi_{s}}}{\partial t} d z+\int_{0}^{h}\left[\overline{\chi_{s}}(z)-\overline{\chi_{s}}(h)\right] \frac{\overline{\partial c_{d}}}{\partial t} d z$,

$\overline{N_{s}}=\left.\overline{w^{\prime} c_{s}^{\prime}}\right|_{h}+\overline{\chi_{s}}\left[\overline{w^{\prime} c_{v}^{\prime}}+\bar{c} \overline{\frac{w^{\prime} T^{\prime}}{\bar{T}}}\right]_{h}+\int_{0}^{h} \overline{\frac{\partial c_{s}}{\partial t}} d z-\overline{\chi_{s}}(h) \int_{0}^{h} \overline{\frac{\partial c_{d}}{\partial t}} d z$

and

$\overline{N_{s}} \approx \overline{c_{d}}(h)\left(\left.\overline{w^{\prime} \chi_{s}^{\prime}}\right|_{h}+\int_{0}^{h} \frac{\overline{\partial \chi_{s}}}{\partial t} d z\right)$

if $\left|\overline{N_{s}}\right| \gg\left|\overline{\chi_{s}}\right|\left|\overline{N_{\mathrm{CO}_{2}}}\right|$. Note that Eq. (14) listed above uses an equivalent expression for the effective change in storage as shown in Eq. (18).

With the information typically available, the contemporary eddy covariance technique cannot measure the flux of every atmospheric constituent even when a fast response gas analyzer with sufficient accuracy is available. The condition $\left|\overline{N_{s}}\right| \gg\left|\overline{\chi_{s}}\right|\left|\overline{N_{\mathrm{CO}_{2}}}\right|$ is required because Eqs. (14), (15) and (22) are derived with the assumption that there is no net ecosystem source or sink of dry air $\left(\overline{N_{d}}=0\right) . \mathrm{N}_{2}$ and $\mathrm{O}_{2}$ are two examples of gas species whose fluxes cannot be measured with the contemporary eddy covariance technique unless the fluxes of other non-water vapor gases are known and the ecosystem $\mathrm{O}_{2}: \mathrm{CO}_{2}$ molar exchange ratio is given.

Eq. (22) approximates $\overline{N_{s}}$ by the product of dry air density at the eddy covariance measurement height and the net ecosystem exchange of the quantity 'mixing ratio' $\left.\overline{w^{\prime} \chi_{s}^{\prime}}\right|_{h}+\int_{0}^{h}\left(\overline{\partial \chi_{s}} / \partial t\right) d z$. Some error may occur if it is used. However, measurements made at the Missouri Ozark AmeriFlux site indicated that the error in the effective change in storage term was less than $5 \%$ for $95 \%$ of the time (Fig. 7), a finding consistent with theoretical expectations. The convenience in the application of Eq. (22) thus outweighs its small error. Further simplification by using a single measurement at tower-top with the implicit assumption that there is no vertical gradient in mixing ratio can cause substantial biases and this method should be avoided. We emphasize that an adequately designed profile system for measuring the effective change in storage in proper units is as important as the eddy flux term for determining NEE.

Eqs. (14), (15) and (22) are valid for mass fluxes in horizontally homogeneous air flows under non-steady state conditions. In contrast, the theory of Webb, Pearman and Leuning (1980) applied for horizontally homogeneous mass fluxes under steady-state conditions and hinged upon the governing constraint of zero mean vertical flux of dry air across the eddy covariance measurement 
plane. Leuning (2007) showed that the vertical eddy flux term does not differ between the steady- and non-steady state conditions. However, it is necessary to account for positive or negative fluxes of dry air across the eddy covariance measurement plane under non-steady state conditions which arise when temperature and pressure change or when a meteorological front passes over the site. Without doing so, measurements of net ecosystem exchange can be biased, diurnally and seasonally. Thus in support of previous researchers (Leuning, 2004, 2007; Kowalski and Serrano-Ortiz, 2007; Lee and Massman, 2011), we recommend that the flux community adopt the non-steady state theory and Eqs. (14), (15) or (22) for horizontally homogeneous mass fluxes.

For non-homogeneous mass fluxes, the general fundamental equation of eddy covariance is

$$
\begin{aligned}
\overline{N_{s}}= & \left.\overline{c_{d}} \overline{w^{\prime} \chi_{s}^{\prime}}\right|_{h}+\overline{\chi_{s}}(h) \overline{N_{d}}+\left\{\int_{0}^{h} \overline{\frac{\partial c_{s}}{\partial t}} d z-\overline{\chi_{s}}(h) \int_{0}^{h} \overline{\frac{\partial c_{d}}{\partial t}} d z\right\} \\
& +\left\{\int_{0}^{h} \nabla_{H} \cdot\left(\overline{\mathbf{u} c_{d}} \overline{\chi_{s}}+\overline{c_{d}} \overline{\mathbf{u}^{\prime} \chi_{s}^{\prime}}\right) d z-\overline{\chi_{s}}(h) \int_{0}^{h} \nabla_{H} \cdot\left(\overline{\mathbf{u} c_{d}}\right) d z\right\}
\end{aligned}
$$

It is possible to approximate the general fundamental equation of eddy covariance with

$\overline{N_{s}} \approx \overline{c_{d}}(h)\left\{\left.\overline{w^{\prime} \chi_{s}^{\prime}}\right|_{h}+\int_{0}^{h} \nabla_{H} \cdot\left(\overline{\mathbf{u}^{\prime} \chi_{s}^{\prime}}\right) d z+\int_{0}^{h} \frac{\overline{\partial \chi_{s}}}{\partial t} d z\right\}$.

However, further investigation is needed to ascertain the accuracy of this approximation.

\section{Acknowledgements}

Dr. Dennis Baldocchi and two anonymous reviewers are thanked for critical comments and suggestions which led to substantial improvement of the paper. The study was carried out in Oak Ridge National Laboratory (ORNL) with support from U.S. Department of Energy, Office of Science, Biological and Environmental Research Program, Climate and Environmental Sciences Division. ORNL is managed by UT-Battelle, LLC, for the U.S. Department of Energy under contract DE-AC05-00OR22725. U.S. Department of Energy support for the University of Missouri (Grant DE-FG02-03ER63683) is gratefully acknowledged. Work by RL was supported in part by the Australian Department of Climate Change and Energy Efficiency through the Australian Climate Change Science Program in CSIRO.

\section{Appendix A. The fundamental equation of eddy covariance (FQEC)}

Begin with the equation of continuity of a specified atmospheric constituent $s$.

$$
\frac{\partial c_{s}}{\partial t}+\nabla \cdot\left(\mathbf{v} c_{d} \chi_{s}+\mathbf{J}_{s}\right)=S_{s}
$$

where $\mathbf{v}$ is the ambient 3D velocity field; $\mathbf{J}_{s}$ is the 3D diffusional flux $\left(\mathrm{mol} \mathrm{m}^{-2} \mathrm{~s}^{-1}\right)$, which for the present discussion will consist only of a vertical component [i.e., $\mathbf{J}_{S}=\left(0,0, J_{s}\right)$ ]; and $S_{s}$ is the source/sink intensity of $s\left(\mathrm{~mol} \mathrm{~m}^{-3} \mathrm{~s}^{-1}\right)$. Molecular transport is usually ignored when discussing atmospheric transport, but this term is useful and germane to the present discussion and so it will be included here. Applying Reynolds averaging to this equation yields (to a high degree of accuracy)

$\overline{\frac{\partial c_{s}}{\partial t}}+\nabla_{H} \cdot\left(\overline{\mathbf{u} c_{d}} \overline{\chi_{s}}+\overline{c_{d}} \overline{\mathbf{u}^{\prime} \chi_{s}^{\prime}}\right)+\frac{\partial}{\partial z}\left(\overline{w c_{d}} \overline{\chi_{s}}+\overline{c_{d}} \overline{w^{\prime} \chi_{s}^{\prime}}+\overline{J_{s}}\right)=\overline{S_{s}}$
Here we have separated the horizontal and vertical components, so that $\mathbf{u}$ is the 2D horizontal velocity and $\nabla_{H}$ is the 2D horizontal gradient operator. Next integrate this equation vertically from the soil surface to some arbitrary height, $h$ (which can be, but is not necessarily, above the canopy top). This yields

$$
\begin{gathered}
\int_{0}^{h} \overline{\frac{\partial c_{s}}{\partial t}} d z+\int_{0}^{h} \nabla_{H} \cdot\left(\overline{\mathbf{u} c_{d}} \overline{\chi_{s}}+\overline{c_{d}} \overline{\mathbf{u}^{\prime} \chi_{s}^{\prime}}\right) d z \\
+\left.\left(\overline{w c_{d}} \overline{\chi_{s}}+\overline{c_{d}} \overline{w^{\prime} \chi_{s}^{\prime}}+\overline{J_{s}}\right)\right|_{0} ^{h}=\int_{0}^{h} \overline{S_{s}} d z .
\end{gathered}
$$

At this point it is fair to say the term $\overline{c_{d}}(h) \overline{w^{\prime} \chi_{s}^{\prime}}(h)$ is the measured eddy covariance flux (or the turbulent dry air mixing ratio flux). It inherently includes the density terms, which WPL 1980 (and some previous and subsequent researchers) have identified and argued as necessary for a complete description of the turbulent trace gas surface exchange flux. The dilemma that WPL 1980 (and again subsequent researchers) have had to face is what to do with the 'quasi-advective term', $\overline{w c_{d}}(h) \overline{\chi_{s}}(h)$. In WPL 1980, this term was zero as a consequence of their assumptions. Realizing the limitation of WPL 1980, Leuning (2004) and Lee and Massman (2011) provided a different approach for dealing with it. The present discussion takes a similar, but more transparent, approach to this term. Specifically, we show here that it can be eliminated from Eq. (A2) rather simply by employing the conservation of mass of dry air with a strategy that is a dynamic equivalence to what is used in Section 2 of the main text.

First, begin with Reynolds averaging the equation of continuity for dry air. This yields

$\overline{\frac{\partial c_{d}}{\partial t}}+\nabla_{H} \cdot\left(\overline{\mathbf{u} c_{d}}\right)+\frac{\partial}{\partial z}\left(\overline{w c_{d}}+\overline{J_{d}}\right)=\overline{S_{d}}$.

Next, integrate this last equation from 0 to $h$ and then multiply the resulting equation by $\overline{\chi_{s}}(h)$. This yields

$$
\begin{aligned}
& \overline{\chi_{s}}(h) \int_{0}^{h} \frac{\overline{\partial c_{d}}}{\partial t} d z+\overline{\chi_{s}}(h) \int_{0}^{h} \nabla_{H} \cdot\left(\overline{\mathbf{u} c_{d}}\right) d z+\left.\overline{\chi_{s}}(h)\left(\overline{w c_{d}}+\overline{J_{d}}\right)\right|_{0} ^{h} \\
& =\overline{\chi_{s}}(h) \int_{0}^{h} \overline{S_{d}} d z .
\end{aligned}
$$

Finally, subtract Eq. (A4) from Eq. (A2) and assume that molecular transport (diffusion) within the free atmosphere is always small enough to ignore (i.e., $\overline{J_{s}}(h) \approx 0$ and $\overline{J_{d}}(h) \approx 0$ for $h \gg 0$ ]. After some simple manipulations, we obtain

$$
\begin{aligned}
& \left\{\int_{0}^{h} \frac{\overline{\partial c_{s}}}{\partial t} d z-\overline{\chi_{s}}(h) \int_{0}^{h} \overline{\frac{\partial c_{d}}{\partial t}} d z\right\}+\left\{\int_{0}^{h} \nabla_{H} \cdot\left(\overline{\mathbf{u} c_{d}} \overline{\chi_{s}}+\overline{c_{d}} \overline{\mathbf{u}^{\prime} \chi_{s}^{\prime}}\right) d z\right. \\
& \left.-\overline{\chi_{s}}(h) \int_{0}^{h} \nabla_{H} \cdot\left(\overline{\mathbf{u} c_{d}}\right) d z\right\}+\left.\overline{c_{d}} \overline{w^{\prime} \chi_{s}^{\prime}}\right|_{h}+\overline{\chi_{s}}(h)\left\{\int_{0}^{h} \overline{S_{d}} d z\right. \\
& \left.+\overline{w c_{d}}(0)+\overline{J_{d}}(0)\right\}=\int_{0}^{h} \overline{S_{s}} d z+\overline{w c_{s}}(0)+\overline{J_{s}}(0) .
\end{aligned}
$$

Several flux terms at the lower boundary now appear in Eq. (A5). $\overline{J_{s}}(0)$ is the flux of $s$ at the soil surface due to molecular diffusion and may be identified as soil efflux measured with a soil chamber while $\overline{w c_{s}}(0)$ may be regarded as an enhanced soil diffusion term due to any pressure pumping effect. Similar interpretations can be made to $\overline{J_{d}}(0)$ and $\overline{w c_{d}}(0)$. Thus,

$\overline{N_{d}}=\int_{0}^{h} \overline{S_{d}} d z+\overline{w c_{d}}(0)+\overline{J_{d}}(0)$,
$\overline{N_{s}}=\int_{0}^{h} \overline{S_{s}} d z+\overline{w c_{s}}(0)+\overline{J_{s}}(0)$. 
This leads to

$\underbrace{\left\{\int_{0}^{h} \frac{\partial c_{s}}{\partial t} d z-\overline{\chi_{s}}(h) \int_{0}^{h} \frac{\partial c_{d}}{\partial t} d z\right\}}_{\text {effective change in storage }}+\underbrace{\left\{\int_{0}^{h} \nabla_{H} \cdot\left(\overline{\mathbf{u} c_{d}} \overline{\chi_{s}}+\overline{c_{d}} \overline{\mathbf{u}^{\prime} \chi_{s}^{\prime}}\right) d z-\overline{\chi_{s}}(h) \int_{0}^{h} \nabla_{H} \cdot\left(\overline{\mathbf{u} c_{d}}\right) d z\right\}}_{\text {horizontal advection }}+\underbrace{\left.\overline{c_{d}} \overline{w^{\prime} \chi_{s}^{\prime}}\right|_{h}}_{\text {eddy flux }}+\underbrace{\overline{\chi_{s}}(h) \overline{N_{d}}}_{\text {dry air source/sink correction }}=\overline{N_{s}}$.

Eq. (A6) is identical to Eq. (8) in the main text except for the additional horizontal advection term. Although the conservation of mass of dry air is used explicitly in the derivation, any atmospheric constituent can be used to constrain flux measurements with the eddy covariance technique as long as its net ecosystem exchange with the atmosphere is known a priori. Eq. (A6) is still valid after relevant variables of dry air in it are replaced with corresponding variables of the new constraining constituent. We term Eq. (A6) the fundamental equation of eddy covariance (FQEC).

In the main text, we showed that by introducing the following two approximations:

$\int_{0}^{h} \overline{c_{d}}(z) \frac{\overline{\partial \chi_{s}}}{\partial t} d z \approx \overline{c_{d}}(h) \int_{0}^{h} \frac{\overline{\partial \chi_{s}}}{\partial t} d z$

and

$\int_{0}^{h} \overline{\chi_{s}}(z) \frac{\overline{\partial c_{d}}}{\partial t} d z \approx \overline{\chi_{s}}(h) \int_{0}^{h} \frac{\overline{\partial c_{d}}}{\partial t} d z$

the effective change in storage can be simplified into

$\int_{0}^{h} \frac{\partial c_{s}}{\partial t} d z-\overline{\chi_{s}}(h) \int_{0}^{h} \overline{\frac{\partial c_{d}}{\partial t}} d z \approx \overline{c_{d}}(h) \int_{0}^{h} \overline{\frac{\partial \chi_{s}}{\partial t}} d z$

without losing much accuracy. The horizontal advection term can also be simplified in a similar way.

$$
\begin{gathered}
\int_{0}^{h} \nabla_{H} \cdot\left(\overline{\mathbf{u} c_{d}} \overline{\chi_{s}}+\overline{c_{d}} \overline{\mathbf{u}^{\prime} \chi_{s}^{\prime}}\right) d z-\overline{\chi_{s}}(h) \int_{0}^{h} \nabla_{H} \cdot\left(\overline{\mathbf{u} c_{d}}\right) d z=\int_{0}^{h}\left[\overline{\chi_{s}}(z)\right. \\
\left.-\overline{\chi_{s}}(h)\right] \nabla_{H} \cdot\left(\overline{\mathbf{u} c_{d}}\right) d z+\int_{0}^{h} \nabla_{H} \cdot\left(\overline{c_{d}} \overline{\mathbf{u}^{\prime} \chi_{s}^{\prime}}\right) d z+\int_{0}^{h} \nabla_{H} \overline{\chi_{s}}(z)
\end{gathered}
$$

$\cdot\left(\overline{\mathbf{u} c_{d}}\right) d z$.

If the following three approximations:

$\int_{0}^{h} \nabla_{H} \cdot\left[\overline{c_{d}(x, y, z)} \overline{\overline{\mathbf{u}^{\prime} \chi_{s}^{\prime}}}\right] d z \approx \overline{c_{d}}(h) \int_{0}^{h} \nabla_{H} \cdot\left(\overline{\overline{\mathbf{u}^{\prime} \chi_{s}^{\prime}}}\right) d z$,

$\int_{0}^{h} \overline{\chi_{s}}(x, y, z) \nabla_{H} \cdot\left(\overline{\mathbf{u} c_{d}}\right) d z \approx \overline{\chi_{s}}(h) \int_{0}^{h} \nabla_{H} \cdot\left(\overline{\mathbf{u} c_{d}}\right) d z$,

and,

$\int_{0}^{h} \nabla_{H} \overline{\chi_{s}}(x, y, z) \cdot\left(\overline{\mathbf{u} c_{d}}\right) d z \approx 0$,

can be made, the horizontal advection term can be reduced to

$$
\begin{aligned}
& \int_{0}^{h} \nabla_{H} \cdot\left(\overline{\mathbf{u} c_{d}} \overline{\chi_{s}}+\overline{c_{d}} \overline{\mathbf{u}^{\prime} \chi_{s}^{\prime}}\right) d z-\overline{\chi_{s}}(h) \int_{0}^{h} \nabla_{H} \cdot\left(\overline{\mathbf{u} c_{d}}\right) d z \approx \overline{c_{d}}(z) \\
& \int_{0}^{h} \nabla_{H} \cdot\left(\overline{\mathbf{u}^{\prime} \chi_{s}^{\prime}}\right) d z .
\end{aligned}
$$

Substituting the approximations (A9) and (A14) into the FQEC (A6) and applying the condition of no dry air source/sink $\left(\overline{N_{d}}=0\right)$ leads to

$\overline{c_{d}}(h)\left\{\int_{0}^{h} \overline{\frac{\partial \chi_{s}}{\partial t}} d z+\int_{0}^{h} \nabla_{H} \cdot\left(\overline{\mathbf{u}^{\prime} \chi_{s}^{\prime}}\right) d z+\left.\overline{w^{\prime} \chi_{s}^{\prime}}\right|_{h}\right\} \approx \overline{N_{s}}$.
The approximations (A11)-(A13) are generalizations of the approximations of (A7) and (A8). They are likely to have reasonable accuracy if the 3D air flows are well-mixed not only vertically but also horizontally even when source/sink distributions of the specified atmospheric constituent are not homogeneous horizontally. However the data presented in this current study neither support nor refute (A11)-(A13). Further studies are needed to investigate how accurate Eq. (A15) is.

In summary, the FQEC and its derivation provide the most transparent method to date for discussing the nature of the approximations and governing constraints that have historically been and are continuing to be imposed on either the FQEC or some of the terms that comprise the FQEC. The following points can be made:

(A) The expression for the 'effective change in storage' results solely from the equations of continuity of dry air and the atmospheric constituent and Reynolds averaging. It is completely independent of any other assumptions.

(B) Exactly the same is true of 'horizontal advection'.

(C) The only requirement for deriving the 'eddy flux' term is Reynolds averaging and the identification of the need to express this flux term in a form that accounts for (or removes) the effects of atmospheric expansion and contraction on measurements of $c_{s}^{\prime}$. But WPL 1980 essentially made this issue synonymous with the assumptions of steady-state horizontally homogeneous air flows that had no dry-air exchange with the soil (i.e., $\overline{w c_{d}} \equiv 0$ ). As this study shows, this identification is not necessary. Nevertheless, WPL's 1980 basic result on the eddy flux term is sound for non-steady state conditions (Leuning, 2007) because the development and manipulation of these concepts and equations are mathematically linear in nature and to a certain extent also independent of one another.

(D) The basic intent behind the development of the FQEC, which is really just another statement of the conservation of mass of an atmospheric constituent, is to define all the other measurements required to estimate 'NEE' by summing (adding and subtracting) the measured terms. Therefore, NEE is not directly measured, but inferred indirectly as a combination of other terms.

(E) Here we propose that the term $\overline{w c_{s}}(0)$ be interpreted as the interaction of the near-surface atmospheric processes with the soil. In the case of $\mathrm{CO}_{2}$ one might then expect this term to be related to (horizontal and vertical) advective flows induced in soils that would enhance the fluxes of $\mathrm{CO}_{2}$ from soils, i.e., to pressure pumping effects. Under most conditions, it is expected to be a relatively small part of $\overline{J_{s}}(0)$ and is included here primarily for the sake of completeness.

(F) WPL 1980 made the condition of no (dry) air exchange at the surface (i.e., $\overline{w c_{d}}(0) \equiv 0$ ) central to their arguments about the eddy flux term. Although we certainly concur that this zero dry air flux boundary condition is a reasonable and supportable assumption for steady-state conditions, under the assumptions of non-steady state, horizontally inhomogeneous conditions, the present discussion shows that it is unnecessary to and independent of 'the effective change in storage term', 'the eddy flux', and 'the dry air source/sink correction term'. It is only under steady-state, horizontally homogeneous conditions that 
this assumption plays an important role because it basically defines the equation of continuity of dry air, which for this one exceptional case can be expressed as $\overline{w c_{d}}(h) \equiv 0$. This, of course, is ultimately WPL's 1980 original governing constraint, which they expressed in terms of a mean (but unmeasurable) dry air drift velocity. The present discussion shows that there is no need to invoke this drift velocity at all.

\section{Appendix B. List of symbols and subscripts}

Symbols
$c$
$h$
$\mathbf{J}$
$k$
$N$
$n$
$P$
$R$
$S$
$t$
$T$
$\mathbf{u}$
$\mathbf{v}$
$w$
$z$
$\chi$

\section{Molar density \\ Eddy flux measurement height}

The vector of the molecular diffusional flux

The ecosystem $\mathrm{O}_{2}$ to $\mathrm{CO}_{2}$ molar exchange ratio

Net ecosystem exchange

The total number of gas components in dry air

Atmospheric pressure

Universal gas constant

Source/sink intensity of an atmospheric constituent

Time

Temperature

Horizontal (2D) wind velocity field

3D wind velocity field

Vertical velocity

Vertical distance from soil surface

$\chi \quad$ The molar density ratio of the specified atmospheric constituent to the constraining constituent; molar mixing ratio when dry air is the constraining constituent

\section{Subscripts}

$s \quad$ The specified atmospheric constituent whose flux is to be measured

$d \quad$ The constraining atmospheric constituent or dry air

$v \quad$ Water vapor

\section{References}

Amiro, B.D., 2001. Paired-tower measurements of carbon and energy fluxes following disturbance in the boreal forest. Global Change Biol. 7, 253-268.

Anthoni, P.M., Law, B.E., Unsworth, M.H., 1999. Carbon and water exchange of an open canopied ponderosa pine ecosystem. Agric. Forest Meteorol. 95, 151-168.

Campbell, J.E., Carmichael, G.R., Chai, T., Mena-Carrasco, M., Tang, Y., Blake, Y.D., Blake, N.J., Vay, S.A., Collatz, G.J., Baker, I., Berry, J.A., Montzka, S.A., Sweeney, C., Schnoor, J.L., Stanier, C.O., 2008. Photosynthetic control of atmospheric carbonyl sulfide during the growing season. Science 322, 1085-1088.

Carrara, A., Kowalski, A.S., Neirynck, J., Janssens, I.A., Yuste, J.C., Ceulemans, R., 2003. Net ecosystem $\mathrm{CO}_{2}$ exchange of mixed forest in Belgium over 5 years. Agric. Forest Meteorol. 119, 209-227.

Craig, H., 1957. Isotopic standards for carbon and oxygen and correction factors for mass spectrometric analysis of carbon dioxide. Geochim. Cosmochim. Acta 12, 133-149.

Farquhar, G.D., Ehleringer, J.R., Hubick, K.T., 1989. Carbon isotope discrimination and photosynthesis. Annu. Rev. Plant Physiol. Plant Mol. Biol. 40, 503-537.

Fuentes, J.D., Wang, D., Gu, L., 1999. Seasonal variations in isoprene emissions from a boreal aspen forest. J. Appl. Meteorol. 38, 855-869.

Fuehrer, P.L., Friehe, C.A., 2002. Flux corrections revisited. Bound.-Layer Meteorol. $102,415-457$.

Galbally, I., Meyer, C.P., Wang, Y.P., Kirstine, W., 2010. Soil-atmosphere exchange of $\mathrm{CH}_{4}, \mathrm{CO}, \mathrm{N}_{2} \mathrm{O}$ and $\mathrm{NO}_{x}$ and the effects of land-use change in the semiarid Mallee system in Southeastern Australia. Global Change Biol. 16, 2407-2419.

Goulden, M.L., Munger, J.W., Fan, S.M., Daube, B.C., Wofsy, S.C., 1996. Measurements of carbon sequestration by long-term eddy covariance: methods and a critical evaluation of accuracy. Global Change Biol. 2, 169-182.

Greco, S., Baldocchi, D.D., 1996. Seasonal variations of $\mathrm{CO}_{2}$ and water vapour exchange rates over a temperate deciduous forest. Global Change Biol. 2, 183-197.

Gu, L., Meyers, T., Pallardy, S.G., Hanson, P.J., Yang, B., Heuer, M., Hosman, K.P., Liu, Q., Riggs, J.S., Sluss, D., Wullschleger, S.D., 2007. Influences of biomass heat and biochemical energy storages on the land surface fluxes and radiative temperature. J. Geophys. Res. 112, D02107, doi:10.1029/2006JD007425.

Gu, L., Meyers, T., Pallardy, S.G., Hanson, P.J., Yang, B., Heuer, M., Hosman, K.P., Riggs, J.S., Sluss, D., Wullschleger, S.D., 2006. Direct and indirect effects of atmospheric conditions and soil moisture on surface energy partitioning revealed by a prolonged drought at a temperate forest site. J. Geophys. Res., D16102, doi:10.1029/2006JD007161.

Gu, L., Falge, E.M., Boden, T., Baldocchi, D.D., Black, T.A., Saleska, S.R., Suni, T., Verma, S.B., Vesala, T., Wofsy, S.C., Xu, L., 2005. Objective threshold determination for nighttime eddy flux filtering. Agric. Forest Meteorol. 128, 179-197.

Hollinger, D.Y., Kelliher, F.M., Byers, J.N., Hunt, J.E., McSeveny, T.M., Weir, P.L., 1994. Carbon dioxide exchange between an undisturbed old growth temperate forest and the atmosphere. Ecology 71, 134-150.

Kammer, A., Tuzson, B., Emmenegger, L., Knohl, A., Mohn, J., Hagedorn, F., 2011. Application of a quantum cascade laser-based spectrometer in a closed chamber system for real-time $\delta^{13} \mathrm{C}$ and $\delta^{18} \mathrm{O}$ measurements of soil-respired $\mathrm{CO}_{2}$. Agric. Forest Meteorol. 151, 39-48.

Keeling, R.F., Piper, S.C., Bollenbacher, A.F., Walker, S.J., 2010. Monthly Atmospheric ${ }^{13} \mathrm{C} /{ }^{12} \mathrm{C}$ Isotopic Ratios for 11 SIO Stations, Trends: A Compendium of Data on Global Change. Carbon Dioxide Information Analysis Center, Oak Ridge National Laboratory, U.S. Department of Energy, Oak Ridge, TN, USA.

King, G.M., Crosby, H., 2002. Impacts of plant roots on soil CO cycling and soilatmosphere CO exchange. Global Change Biol. 8, 1085-1093.

Knohl, A., Schulze, E.-D., Kolle, O., Buchmann, N., 2003. Large carbon uptake by an unmanaged 250-year-old deciduous forest in Central Germany. Agric. Forest Meteorol. 118, 151-167.

Kolari, P., Pumpanen, J., Rannik, Ü., Ilvesniemi, H., Hari, P., Berninger, F., 2004. Carbon balance of different aged Scots pine forests in Southern Finland. Global Change Biol. 10, 1-14.

Kowalski, A.S., Serrano-Ortiz, P., 2007. On the relationship between the eddy covariance, the turbulent flux, and surface exchange for a trace gas such as $\mathrm{CO}_{2}$. Bound.-Layer Meteorol. 124, 129-141.

Lee, X., Massman, W.J., 2011. A perspective on thirty years of the Webb, Pearman and Leuning density corrections. Bound.-Layer Meteorol. 139, 37-59.

Leuning, R., 2004. Measurements of trace gas fluxes in the atmosphere using eddy covariance: WPL corrections revisited. In: Lee, X., Massman, W., Law, B. (Eds.), Handbook of Micrometeorology: A Guide for Surface Flux Measurements and Analysis. Kluwer Academic Publishers, Dordrecht, Netherlands, pp. 119-132.

Leuning, R., 2007. The correct form of the Webb, Pearman and Leuning equation for eddy fluxes of trace gases in steady and non-steady state, horizontally homogeneous flows. Bound.-Layer Meteorol. 123, 263-267.

McDermitt, D., Burba, G., Xu, L., Anderson, T., Komissarov, A., Riensche, B., Schedlbauer, J., Starr, G., Zona, D., Oechel, W., Oberbauer, S., Hastings, S., 2011. A new low-power, open-path instrument for measuring methane flux by eddy covariance. Appl. Phys. B-Lasers Opt. 102, 391-405.

Meijide, A., Cardenas, L.M., Bol, R., Bergstermann, A., Goulding, K., Well, R., Vallejoa, A., Scholefield, D., 2010. Dual isotope and isotopomer measurements for the understanding of $\mathrm{N}_{2} \mathrm{O}$ production and consumption during denitrification in an arable soil. Eur. J. Soil Sci. 61, 364-374.

Pallardy, S.G., Nigh, T.A., Garrett, H.E., 1988. Changes in forest composition in central Missouri: 1968-1982. Am. Midland Nat. 120, 380-390.

Paw, U.K.T., Baldocchi, D.D., Meyers, T.P., Wilson, K.B., 2000. Correction of eddycovariance measurements incorporating both advective effects and density fluxes. Bound.-Layer Meteorol. 97, 487-511.

Pilegaard, K., Hummelshøj, P., Jensen, N.O., Chen, Z., 2001. Two years of continuous $\mathrm{CO}_{2}$ eddy-flux measurements over a Danish beech forest. Agric. Forest Meteorol. 107, 29-41.

Priante-Filho, N., Vourlitis, G.L., Hayashi, M.M.S., Nogueira, J.D., Campelo, J.H., Nunes, P.C., Souza, L.S.E., Couto, E.G., Hoeger, W., Raiter, F., Trienweiler, J.L., Miranda, E.J., Priante, P.C., Fritzen, C.L., Lacerda, M., Pereira, L.C., Biudes, M.S., Suli, G.S., Shiraiwa, S., Do Paulo, S.R., Silveira, M., 2004. Comparison of the mass and energy exchange of a pasture and a mature transitional tropical forest of the southern Amazon Basin during a seasonal transition. Global Change Biol. 10, 863-876.

Seibt, U., Brand, W.A., Heimann, M., Lloyd, J., Severinghaus, J.P., Wingate, L., 2004. Observations of $\mathrm{O}_{2}: \mathrm{CO}_{2}$ exchange ratios during ecosystem gas exchange. Global Biogeochem. Cycles 18 (Article Number: GB4024).

Tuzson, B., Hiller, R.V., Zeyer, K., Eugster, W., Neftel, A., Ammann, C., Emmenegger, L., 2010. Field intercomparison of two optical analyzers for $\mathrm{CH}_{4}$ eddy covariance flux measurements. Atmos. Meas. Tech. 3, 1519-1531.

Vilà-Guerau de Arellano, J.V., Duynkerke, P.G., Zeller, K.F., 1995. Atmospheric surface layer similarity theory applied to chemically reactive species. J. Geophys. Res. 100 (D1), 1397-1408.

Vourlitis, G.L., Priante-Filho, N., Hayashi, M.M.S., Nogueira, J.D., Caseiro, F.T., Campelo Jr., J.H., 2001. Seasonal variations in the net ecosystem $\mathrm{CO}_{2}$ exchange of a mature Amazonian transitional tropical forest (cerradão). Funct. Ecol. 15, 388-395.

Webb, E.K., Pearman, G.I., Leuning, R., 1980. Correction of flux measurements for density effects due to heat and water vapor transfer. Quart. J. R. Meteorol. Soc. 106, 85-100.

Welsh, D.T., Bartoli, M., Nizzoli, D., Castaldelli, G., Riou, S.A., Viaroli, P., 2000. Denitrification, nitrogen fixation, community primary productivity and inorganic-N and oxygen fluxes in an intertidal Zostera noltii meadow. Mar. Ecol.-Prog. Ser. 208, 65-77.

Wilson, K., Goldstein, A., Falge, E., Aubinet, M., Baldocchi, D., Berbigier, P., Bernhofer, C., Ceulemans, R., Dolman, H., Field, C., Grelle, A., Ibrom, A., Law, B.E., Kowalski, A., Meyers, T., Moncrieff, J., Monson, R., Oechel, W., Tenhunen, J., Valentini, R., Verma, S., 2002. Energy balance closure at FLUXNET sites. Agric. Forest Meteorol. $113,223-243$. 
Yang, B., Hanson, P.J., Riggs, J.S. Pallardy, S.G., Heuer, M.. Hosman, K.P., Meyers, T.P., Wullschleger, S.D., Gu, L., 2007. Biases of $\mathrm{CO}_{2}$ storage in eddy flux measurements in a forest pertinent to vertical configurations of a profile system and $\mathrm{CO}_{2}$ density averaging. J. Geophys. Res. 112, D20123, doi:10.1029/2006JD008243.

Yang, B., Pallardy, S.G., Meyers, T.P., Gu, L., Hanson, P.J., Wullschleger, S.D., Heuer, M., Hosman, K.P., Riggs, J.S., Sluss, D.W., 2010. Environmental controls on water use efficiency during severe drought in an Ozark forest in Missouri, USA. Global Change Biol. 16, 2252-2271.

Yang, P.C., Black, T.A., Neumann, H.H., Novak, M.D., Blanken, P.D., 1999. Spatial and temporal variability of $\mathrm{CO}_{2}$ concentration and flux in a boreal aspen forest. J. Geophys. Res. 104 (D22), 27653-27661. 